\title{
Credit Risk and the Yen Interest Rate Swap Market
}

\author{
by \\ Young Ho Eom \\ Yonsei University \\ Marti G. Subrahmanyam \\ New York University \\ Jun Uno \\ Nikkei QUICK Information Technologies, Inc.
}

First Version: March 1997

This Version: July 2000

Keywords: Credit Risk, Japanese Government Bonds Market, Swap Pricing

JEL Classification: G12, G13, G15

Correspondence: Marti G. Subrahmanyam, Department of Finance, Leonard Stern School of Business, New York University, 44 West 4th Street, New York, NY 10012-1126. e-mail: msubrahm@stern.nyu.edu. Tel: (212) 998-0348. Fax: (212)995-4233.

We thank Anurag Gupta, Jean Helwege and Frank Packer for their helpful comments on previous drafts of the paper, and Paolo Pasquariello for able research assistance. We also thank Mitsue Hamano, who helped us in assembling the data series analyzed in the paper. We would like to acknowledge research support from the Center for Japan-U.S. Business and Economic Studies, Stern School of Business, New York University. 


\title{
Credit Risk and the Pricing of Japanese Yen Interest Rate Swaps
}

\begin{abstract}
:
In this paper, we investigate the pricing of Japanese yen interest rate swaps during the period 1990-96. We obtain measures of the spreads of the swap rates over comparable Japanese Government Bonds (JGBs) for different maturities and analyze the relationship between the swap spreads and credit risk variables.

Our empirical results in the yen swap market indicate that: 1) the commonly-used assumption of lognormal default-free interest rates and swap spreads is strongly rejected by the data, 2) the term structure of swap spreads displays a humped-shape, and 3) the shocks in the yen swap spread are negatively correlated with the shocks in the comparable default-free spot rates, especially for longer maturities.

Our analysis also indicates that yen swap spreads behaved very differently from the credit spreads on Japanese corporate bonds in the early nineties. In contrast to Japanese corporate bonds, we find that the yen swap spread is also significantly related to proxies for the longterm credit risk factor. Furthermore, the swap spread is negatively related to the level and slope of the term structure and positively related to the curvature, indicating that the credit "optionality" is priced in the swap rate. Thus, overall, the yen swap market was sensitive to credit risk during the period of our study.
\end{abstract}




\section{Introduction}

The market for interest rate derivatives, in general, and for swaps, in particular, has grown exponentially in the last decade. Recent estimates indicate that the notional outstanding volume of transactions of privately negotiated (over-the-counter) derivatives at the end of 1997 amounted to over $\$ 29$ trillion, of which interest rate swaps amounted to over $\$ 22.3$ trillion. Given the importance of the yen in international trade and finance, it is not surprising that yen interest rate swaps form a substantial proportion of this volume (about 19.5\%), second only to those denominated in dollars (about $27.3 \%)^{1}$

The phenomenal growth in the volume of transactions in the swap market has led to increased scrutiny of the credit risk being borne by the major banks that are the principal swap dealers. In general, the credit risk of swaps is related to the default risk in fixed income markets. However, in the yen fixed income market, due to certain regulatory constraints in Japan, the issue of credit risk was somewhat clouded until the early 1990's. Certain banks and utility companies were able to raise debt at low rates relative to government securities. ${ }^{2}$ In addition to regulatory constraints and the absence of liquidity in the secondary market, there was a widespread perception that the financial system had virtually eliminated credit risk. This could be ascribed partly to the fact that defaults by large companies were extremely rare, and partly to the security blanket offered by the main banks, and ultimately, the central bank. All this has changed in recent years with the slower economic growth and the failures and public rescues of some of the major financial institutions in Japan. Prominent examples include Yamaichi Securities, one of the four largest securities firms in Japan, and the Long Term Credit Bank of Japan and the Nippon Credit Bank, two of the three long term lending institutions in Japan. The issue, therefore, is whether the perceived inefficiency of the Japanese yen bond market in pricing credit risk also spilled over into the swap market. If the yen swap market also mispriced credit risk, then questions would be raised about the efficiency of one of the most liquid markets in the world, which has both low transaction costs and is globally integrated with swap markets in other currencies.

In the absence of credit or liquidity risks, standard ("plain vanilla") interest rate swaps can be priced using the current term structure of interest rates based on Treasury bond quotations. However, credit risk adds an important dimension to the pricing of over-thecounter derivative instruments. The important characteristic of over-the-counter derivatives that distinguishes them from exchange-traded products is that they are not backed by the guarantee of a clearing corporation or exchange. Hence, each of the two counterparties to the transaction is exposed to the default risk of the other. This default risk is particularly

\footnotetext{
${ }^{1}$ Source: International Swaps and Derivatives Association

${ }^{2}$ For instance, until 1992, all three major long-term credit banks in Japan issued bonds at the same rate, or sometimes even lower than that of comparable government bonds, despite differences in credit quality between them and relative to the government. This was also true of some utility companies. For instance, the Tokyo Electric Company issued bonds at rates below those yielded by comparable government bonds, while in the secondary market, almost immediately thereafter, yields rose to 20 basis points higher than for similar government bonds.
} 
important for long-dated instruments such as interest rate swaps.

Swaps are typically negotiated as zero-value transactions when they are initiated, with the swap rate being defined as the fixed rate to be exchanged for a floating rate such as LIBOR. However, their value changes over time as interest rates fluctuate. In the case of a fixed-for-floating interest rate swap, as long-term interest rates rise, the fixed rate payer benefits from being locked into the lower interest rate. Consequently, the value of the fixed side moves "in-the-money." By the same token, the floating rate payer receives flows that are lower than the changed interest rates would dictate, and hence, the value of the floating side moves "out-of-the-money." The opposite occurs when long-term interest rates decline. Default risk arises when the entity for which the swap is out-of-the-money is unable to meet its commitments to the counterparty for which the swap is in-the-money.

In an efficient market, one would expect market swap rates to incorporate the risk of default, if the counterparties rationally anticipate this possibility. Hence, one would expect the swap rates to be sensitive to the credit ratings of the counterparties. For instance, a swap dealer who pays a floating rate and receives fixed payments in exchange would require a BBB-rated counterparty to pay a higher fixed rate compared to a AAA-rated counterparty. Conversely, the dealer would be willing to make lower fixed payments in exchange for floating rate payments to a BBB-rated counterparty than a AAA-rated counterparty. Hence, the swap spread, defined as the difference between the swap rate and the yield on a par Treasury bond with the same maturity, should be greater for the BBB-rated counterparty than the AAA-rated counterparty, and so also should be the differences between the bid and the offer rates.

As discussed by Litzenberger (1992), this is not always observed explicitly in the market swap rates. Several reasons have been suggested for this phenomenon. First, the swap contract is neither an asset nor a liability for either counterparty, since it is based on the difference between two streams of cash flows, (including the principal amounts, which net out to zero for interest rate swaps). Hence, as also pointed out by Duffie and Huang (1996) and $\mathrm{Li}$ (1998), the differences between the swap rates for counterparties with different credit ratings should be much less than the differences between the rates for the corresponding debt of the same maturity. Second, there may be credit enhancement devices (collateral, margining, credit triggering clauses, etc.) for the lower-quality counterparties that effectively reduce the differences in credit quality across borrowers. Lastly, there may be credit rationing which implies that poorly-rated firms are simply rationed out of the swap market. These explanations suggest that market swap spreads over default-free instruments ought to be smaller than the spreads in the debt market for comparable maturities. However, swap spreads should, at least partly, be determined by credit risk considerations. Counterparties with poorer credit ratings should be quoted higher spreads, while dealers with better credit ratings should demand smaller spreads. In addition, since the market swap rates reflect the weighted average of the credit ratings of the various counterparties, they should include a positive spread to the default-free rates. 
The other factor that may influence the pricing of swaps is liquidity risk. Several authors have noted that liquidity effects influence the yields in the fixed income securities market. ${ }^{3}$ As argued by Grinblatt (1995), this convenience yield spills over into the swap market, since "[it] is lost to an investor wishing to receive fixed rate payments, who in lieu of purchasing a Treasury note, enters into a swap to receive fixed payments." 4 Thus, positive swap spreads may be at least partly explained by liquidity considerations, if the Treasury market is more liquid than the swap market.

We investigate these issues in the context of the yen swap market in the nineties. The purpose of this paper is to examine the pricing of Japanese yen interest rate swaps during the period 1990-96. Using the Japanese Government Bonds (JGBs) issued by the Japanese Treasury as the basis for comparison, we obtain measures of the spreads of the swap rates over comparable JGBs, for different maturities, during the period of our investigation. We use alternative methods to estimate the JGB spot interest rate curve and define the spreads of the swap rates over the comparable default-free rates. However, in addition to the defaultfree term structure, other factors such as credit risk, liquidity and other frictional effects, as well as the yield spreads in related swap markets influence the pricing of yen interest rate swaps. We examine these effects by analyzing the relationship between swap spreads estimated by alternative methods and proxies for these explanatory variables. We present evidence on two aspects of the yen interest rate swap market. First, we present a detailed empirical analysis of the yen interest rate swap market in the nineties. Second, we provide some results on the relationship between the yen and dollar interest rate swap markets.

Section 2 of the paper surveys the literature on the swap market, mainly in the U.S. dollar context. Section 3 describes the JGB and yen swap markets, lists the data sources and provides summary statistics. Section 4 presents the alternative methods we use for estimation of the term structure of interest rates based on data from the JGB market and summarizes these results. It also discusses the methods used for estimation of the term structure of interest rates implied by the default-free JGB market as well as the swap market. Alternative hypotheses on the pricing of swaps and the determinants of the swap spread are presented in Section 5. Estimates of the swap spreads and tests of alternative hypotheses explaining the spreads are also presented in this section. Section 6 concludes the paper and suggests directions for future research.

\footnotetext{
${ }^{3}$ Boudoukh and Whitelaw (1993), Duffie (1996), and Elton and Green (1998) argue that there are often significant differences between on-the-run ("special") Treasury securities and comparable off-the-run instruments. This is explained as a liquidity-based convenience yield available to holders of certain Treasury bonds.

${ }^{4}$ Grinblatt (1995) considers and rules out various explanations for the lower yields on U.S. Treasury securities such as preferential taxation, availability for posting collateral, regulatory advantage and market segmentation. He focuses on lower bid-offer spreads and immediacy as the only explanation for the convenience yield offered by Treasury securities.
} 


\section{Credit Risk and Swap Spread: The Hypotheses}

The empirical issue we examine in this paper is whether swap rates reflect credit risk in the Japanese yen interest rate swap market. In the absence of credit risk, as well as market frictions such as illiquidity and tax effects, a standard interest rate swap can be thought of as the exchange of a fixed rate bond for a floating rate bond. Pricing the swap in this simple setting is fairly straightforward. Since the floating rate bond on the reset date is valued at par when there is no risk of default, the mark-to-market value of an existing swap on a reset date is simply the difference between par and the present value of the cash flows on the fixed side. On a date between resets, the floating side will include the payment based on the last reset. The market swap rate is then defined as the rate that sets the mark-to-market value of the swap to zero, which would be the same as the yield on a par bond of the same maturity.

If there is some risk of default, the simple decomposition of the swap into the difference between a fixed- and a floating-rate bond breaks down, since the cash flows are subject to the risk of default. In order to price swaps in the presence of default risk, it is necessary to model the default risk explicitly. As pointed out by Duffie and Singleton (1997), there are two broad approaches to the problem of valuing corporate contingent claims in the presence of default risk. The first is the "structural" approach, proposed by Merton (1974) in the context of risky zero-coupon debt. In this approach, the limited liability aspect of equity is modeled as an option on the firm's assets. The other approach uses the "reducedform" of the underlying structure, and, therefore, does not directly deal with the capital structure, the rules governing default and other characteristics of the counterparties to the swap transaction. Thus, the precise impact of default risk on the swap rates depends on the parameterizations of the stochastic processes governing probability of default. Regardless of modeling assumptions, however, the swap rates should, in general, be different from the par yield for the riskfree bond if default risk is present. In other words, the swap spread is, in general, non-zero. We state this as a testable null hypothesis:

$H_{0}(1)$ : In the absence of credit risk and market frictions, swap spreads should always be zero.

There are only a few empirical papers in the academic literature that test the impact of credit risk on the pricing of swaps, and most of them deal with U.S. dollar interest rate swaps. ${ }^{5}$ In the case of U.S. dollar interest rate swaps, Sun, Sundaresan and Wang (1993) empirically test the null hypothesis that swap rates over par yields of Treasury bonds are all zero. Using swap rates and par yields on corresponding Treasury bonds for the sample period from October 11, 1988 to April 15, 1991, they find that swap spreads are significantly positive for all maturities irrespective of the shape of the yield curve. Furthermore, they find that term premiums of swap spreads increase significantly with maturity, although the increase is smaller when the yield curve is inverted. The second issue that Sun, Sundaresan

\footnotetext{
${ }^{5}$ For instance, in the case of the yen swap market, we have come across only one paper (in Japanese) by Hamano (1997).
} 
and Wang investigate is the proposition that while the default risk of a counterparty increases both the coupon rate on a par bond yield based on LIBOR rates as well as the swap rate, the effect is more pronounced on the bond yields than on the swap rates. ${ }^{6}$ In order to test this hypothesis, they take the difference between LIBID par bond yields and swap offer rates, and test whether the differences are zero. Their overall empirical results confirm that dollar interest swap rates reflect credit risk, although the low correlations of changes in swap rates and LIBOR par bond yields may indicate that their empirical results are due to the use of non-synchronous data - LIBOR data are collected from London and swap quotes are obtained from the U.S. markets, at different times of the day. ${ }^{7}$

Mozumdar (1996) also tested whether quoted swap rates reflect the counterparty credit risk. He uses a non-linear specification for swap pricing and estimates a parameter that proxies for the fraction of the promised cash flows that are not received in the event of default. Since the distribution of errors from this estimation is difficult to specify, he uses the Generalized Method of Moments (GMM) to estimate the default risk parameter, using two alternative sets of data from dollar and DM swaps during the period 1990 to 1996. His broad conclusion is that the default risk parameter is positive and statistically significant, in the case of dollar swaps. However, the effect is weaker for the longer maturities, which he attributes to the use of credit enhancement devices. More specifically, the estimation of the default risk parameter shows that the impact of default risk on swap rates is less than for the corresponding bond yields. In contrast, for DM swaps, Mozumdar finds that the results are statistically insignificant.

Rather than measuring the swap yield spreads over Treasury yields, Duffie and Singleton (1997) calculate the swap spreads over Treasuries using zero-coupon yields ("spot spreads"). In order to estimate the swap zero-coupon yields, they use a specific two-factor square-root model along the lines proposed by Cox, Ingersoll and Ross (1985), where the factors are extracted from the two-year and the ten-year swap rates, which are assumed to be observed without error. Hence, in their empirical specification, the model exactly fits two points on the observed swap yield curve, and is estimated using the joint likelihood of swap yields at several maturities. They find that swap spreads are positive at all maturities, and the term structure of swap spreads is on average upward sloping, from 22 basis points for the six-month spread up to about 42 basis points for the five-year spread, while the spreads are nearly constant beyond five years to ten years at about 41-42 basis points.

There are both advantages and disadvantages of using the implied spot rates as opposed

\footnotetext{
${ }^{6}$ This is consistent with the theoretical models proposed by Duffie and Huang (1996), Jarrow and Turnbull (1997), Li (1998) and Huge and Lando (2000).

${ }^{7}$ Sun, Sundaresan and Wang (1993) also look at the same issue at a micro-level by using the quoted bids and offers from two swap dealers [AIG Financial Products and Merrill Lynch] with different credit ratings for their long-term debt [AAA and A respectively]. They test and confirm the hypothesis that given that default risk is priced, the bid-offer spread for the higher-rated dealer should be larger than for the lower-rated one, in the U.S. dollar swap market. Although their findings could be viewed as confirmation that credit risk is priced in swap quotes, they may also be explained by more aggressive pricing by the lower-rated dealer. More detailed investigation is called for to distinguish between these two competing explanations.
} 
to the par bond yields. First, since the implied spot rates for swaps and Treasury bonds are specific to the maturity under consideration, whereas the yields to maturity are complex weighted averages of the spot rates for different maturities, the spreads based on spot rates can be clearly identified with a particular maturity. Second, the implied spot rates directly translate into the forward interest rates that are used to value other derivative securities related to swaps, such as bond options, caps, floors and swaptions. However, the implied spot rates are obtained by "bootstrapping" bond yields of different maturities. Hence, if maturity-specific effects are important, these cannot be clearly identified, since the estimation procedure distributes the effects across different maturities. For example, if there are maturity-specific effects such as the liquidity of JGBs in the 7-10 years sector, the estimated spot rates for all maturities are contaminated, and hence misleading, because the liquidity factor in that segment will "spill-over" into spot rates in other maturities. This happens because the bond prices used in the estimation are essentially based on a portfolio of zerocoupon rates, and it is difficult to isolate the spot rates from them without the liquidity effects. To mitigate such problems, it is better to analyze interest rate swaps using both measures.

If credit risk is reflected in market swap rates, one way to measure empirically the importance of credit risk is to examine the relationship between proxies of default risk and the market swap spreads. As discussed in the introduction, the theoretical models of Duffie and Huang (1996), Jarrow and Turnbull (1997), Li (1998) and Huge and Lando (2000) suggest that swap rates should change with respect to changes in the default risk premium of corporate bonds; however, the magnitude of the change in swap rates should be much smaller due to the differences in contractual features of swaps and corporate bonds. For instance, Jarrow and Turnbull (1997) calibrate their model in an upward-sloping default spread environment and find that a 100 basis-point yield difference between counterparties results in less than 2 basis points difference for a five-year swap, which is consistent with the results of Duffie and Huang (1996) and Huge and Lando (2000). Thus, the testable implication of default risk on the swap spreads can be stated in the following null hypothesis:

$H_{0}(2)$ : In the absence of credit risk in the market, swap spreads should be unrelated to the default risk premium on corporate bonds.

In a recent study, Minton (1997) examines the pricing of U.S. dollar interest rate swaps based on two alternative models. The first is related to the prices of Eurodollar futures contracts, and the second to corporate bond prices. She finds that market swap rates are highly correlated with rates implied by Eurodollar futures prices, although the two series do not move one-for-one. ${ }^{8}$ She also finds that swap rates are significantly related to par corporate bond yields. Her empirical results, based on dollar interest rate swaps, indicate

\footnotetext{
${ }^{8}$ She ascribes this lack of perfect correspondence to the difference in credit risk between the two contracts: swaps are traded over-the-counter and, therefore, carry counterparty risk, while futures contracts are exchange traded, and have negligible counterparty risk, due to the intermediation of the clearing house. She ignores the effect of the negative convexity of forward contracts compared to futures contracts as pointed out by Gupta and Subrahmanyam (2000). They show that this effect is significant for long-dated swaps in the U.S. dollar market.
} 
that a 100 basis point increase in corporate bond spread over the ten-year treasury yield implies about a 15 basis point increase in ten-year swap spread.

Instead of using corporate bond yields as a measure of the expected credit risk, Brown, Harlow and Smith (1994) test whether swap rates reflect the probability of counterparty default by using the Treasury-Eurodollar (TED) spread in the context of a pure expectations model. They first regress the swap spread on the Treasury yield and the Treasury-Eurodollar (TED) spread and find that the explanatory power of this variable, while significant, is low.

Duffie and Singleton (1997) also find that a higher spread between rates on AA and AAA rated commercial paper, the proxy for default risk, increases the spread for zero coupon swap rates. Furthermore, they use a multivariate vector autoregression (VAR) to check the relative importance of liquidity and credit factors on the swap spreads, and find that credit shocks play an important role over a long horizon in explaining the variations of swap spreads, while the impact of liquidity factors is more short-lived. They conclude, however, that a substantial proportion of the variation in the swap spreads is explained by their own shocks, indicating that swap rates may be influenced by swap market-specific activity.

We can also measure the importance of credit risk by examining the swap spread and the slope of the term structure of interest rates. As pointed out by Sorensen and Bollier (1994) and Mozumdar (1996), there is a positive probability of each counterparty having a negative value position in the future, given the uncertainty in the term structure of interest rates. This suggests the possibility of default on the payments by the counterparty for whom the swap is out-of-the-money (i.e., has negative value) to the counterparty for whom the swap is in-the-money (i.e., has positive value). ${ }^{9}$ This can be illustrated in the context of an upward sloping term structure as discussed by Mozumdar (1996). If counterparty A is a fixed rate payer and counterparty B is a floating rate payer, in the early part of the life of the swap, B is receiving on average more than it pays. Hence, $\mathrm{B}$ is likely to be in-the-money during the early period, and therefore, exposed to default risk. In this setting, counterparty A can be thought of, as argued by Sorensen and Bollier (1994), as owning a series of European-style options, exercisable when it defaults on its payments. Therefore, in an upward (downward)sloping term structure environment, the fixed (floating) rate payer bears more default risk, on average, and hence demands a risk premium through a lower (fixed) rate. We state this as follows:

$H_{0}(3)$ : In the absence of counterparty credit risk, swap spreads should be unrelated to the slope of the term structure of interest rates.

Koticha (1993) empirically tests a negative relationship between the slope of the term structure and the spread between the swap rate and the yield on a Treasury bond of comparable maturity, using data from five currencies, \$, yen, £, DM and FF. The study uses first-differenced daily swap quotes over the period January 1990 to July 1992, for matu-

\footnotetext{
${ }^{9}$ Of course, if the defaulting party is in-the-money, the other counterparty gets a "bonus" if the swap is terminated by a default event triggered by the failure of the defaulting entity to meet another obligation.
} 
rities between 2 years and 10 years. By regressing the swap spreads on the slope of the term structure and a credit risk proxy, Koticha finds that the coefficient of the slope term is negative and significant. Minton (1997) finds that swap rates are related to proxies for the shape of the yield curve and that swap rates are positively related to short-term interest rate volatility, thus suggesting that the option to default is priced in the swap market. Contrary to the results of Koticha (1993), however, she finds that changes in ten-year swap rates are positively related to changes in the slope of the term structure measured by the difference between 30-year Treasury bond yield and 3-month Treasury Bill yield, i.e., swap rates increase as the yield curve steepens.

In this paper, we test all three hypotheses in the context of the yen interest rate swap market. We also study the linkages between the yen and dollar interest rate swap markets.

\section{Data sources}

The swap rates used in this study are the daily bid/offer quotations at the market close (around 5 P.M.,Tokyo time). They are obtained from Nihon Keizai Shimbun's NEEDS database for maturities of two-, three-, four-, five-, seven-, and ten-years. To assess the quality of the swap quotations from NEEDS, we also obtained the swap rates from another source, Data Resources Inc. (DRI) for the same period. These data were available for the period October 1, 1987 to May 17, 1996. However, since data for other variables were available only for a shorter period, only data from April 27, 1990 to May 17, 1996 are used throughout the study.

In order to estimate the yields on non-defaultable bonds, we collected daily closing prices of Japanese Government Bonds (JGBs) of different maturities from the NEEDS database. ${ }^{10}$ We chose to analyze ten-year JGBs due to limited availability of JGB data. Only ten and twenty-year (maturity at issue) JGBs are listed on the Tokyo Stock Exchange and, of these, ten-year JGBs have a regular auction cycle as in the case of the U.S. Treasury bond market. However, we use only the price data from ten-year JGBs since we analyze swaps of maturities of ten years or less in this study. ${ }^{11}$ The prices are based on small-lot transactions from the Tokyo Stock Exchange at 3:00 P.M. ${ }^{12}$ Small-lot transactions have to be concentrated on the organized exchange and prices are set once a day at 3:00 P.M., based on call auctions with prices being quoted in one sen (0.01 yen) increments. In the absence of small orders, major brokers are responsible for providing quotations based on the transaction prices in

\footnotetext{
${ }^{10}$ Ten-year JGBs are usually issued every month. Of the amount issued, 60 percent are auctioned, with the remaining 40 percent being underwritten by the syndicate. Thus, at any point in time, there is a bond maturing almost every month for the next ten years.

${ }^{11}$ The first 20-year JGB was issued in October 1986. Hence, these bonds had more than 10 years to maturity during our sample period. Since the maximum maturity of the swaps studied is only 10 years, the 20-year JGB data are not comparable with the data from the swap market and hence are not analyzed here.

${ }^{12}$ In the subsequent analysis, we choose to use weekly observations (Friday) to reduce potential econometric problems due to nonsynchronous data.
} 
the over-the-counter (OTC) market. ${ }^{13}$ As in the case of the U.S. Treasury bond market, the drawback of using data from the exchange is that the relative trading volume on the exchange is rather small. ${ }^{14}$ Thus, because of sparse trading on the exchange, the prices we obtain may not always be representative and may hence be a noisy representation of the true price. However, the exchange quotations are unlikely to be biased since trades on the exchange are conducted mainly to set an "authorized price," since prices on the Tokyo Stock Exchange are the only prices accepted for the settlement of futures contracts and for financial and tax accounting. Hence, any systematic bias in the prices on the exchange compared to the OTC market is likely to be eliminated by arbitrage.

In order to estimate the spot rates implied in the interbank market and swap market, we obtained daily bid/offer yen TIBOR (Tokyo Inter-bank Offer Rates) data from the NEEDS database. The TIBOR yen rates are available for one-, two-, three-, six-, nine-, and twelvemonth maturities. Again, to assess the quality of the data, we also obtain LIBOR yen data from another source, the DRI database. We also obtained data on the 12 year corporate bonds issued by the Tokyo Electric Company which are used as a proxy for the long term defaultable bonds. ${ }^{15}$ The 3 month repo rate (Gensaki) is used as a proxy for the short term Treasury yield, since Treasury bills were not issued during the earlier part of our sample period.

\subsection{Summary statistics of the data}

Figure 1 plots the three-month yen TIBOR rate, the two- and ten-year swap rates for the period April 27, 1990 to May 17, 1996. These swap rates can be interpreted very roughly as yields to maturity on bonds of the same maturity, priced at par. As the graph shows, swap rates in general have declined during the sample period. Though the swap yield curve was upward sloping during most of the sample period, the swap curve was inverted in 1990 and 1991. Table 1 provides the sample statistics of yen interest rate swap rates for the sample period. Panel A of the table presents the statistics in terms of the levels of the rates, and panel $B$ in terms of first differences. The swap rates are based on the mid-points of the daily bid and offer rates during this period. The term structure of swap rates for the sample period is, on average, upward-sloping, as indicated by the means. Also, the swap rates are persistent and behave approximately like a random walk process, as is the case for yields in other markets. Although the auto-correlation coefficients of the swap rates are close to one, the rates may not exactly be a random walk process, since the standard deviations decline as the swap maturity increases.

\footnotetext{
${ }^{13}$ Large-lot transactions (over 10 million yen) are not required to be traded on organized exchanges. However, when they are traded, orders are matched by a call auction at the market open and close, and continuous auctions are held for the rest of the session.

${ }^{14}$ The proportion of the total volume traded on the exchange was 3.9 percent in 1990, 2.6 percent in 1992, 1.2 percent in 1993 and 1.1 percent in 1994. [Source: Securities Markets in Japan, 1996.]

${ }^{15}$ Reliable data on corporate bonds in Japan are difficult to obtain because of relatively small and thinly traded market. The Tokyo Electric Company's bonds are probably the best available proxy.
} 
Panel B shows that the autocorrelations of the daily changes in the swap rates, however, are generally larger than 0.1 for the short maturities, showing modest mean-reversion. However, the degree of mean-reversion declines substantially for longer maturities. This is consistent with the evidence for Treasury yields in many currencies. The panel also suggests that changes in the swap rates follow a non-normal distribution, and hence, the swap rates, like yields, in general, may not be well- approximated by a lognormal process. Also, relative to the normal distribution, changes in the swap rates show excess positive skewness and kurtosis. The term structure of skewness increases as the maturity increases, but the kurtosis decreases as the maturity increases. One possible explanation for these characteristics may be discontinuous changes or jumps in the data, another common feature of interest rates.

Table 2 presents summary statistics of the bid-offer spreads of the yen interest rate swap quotations during the period under study from two alternative sources, along with similar data from the dollar interest rate swap market. Panel A of the table provides the means and standard deviations of the spreads for different maturities from April 27, 1990 to May 17, 1996, based on data from the NEEDS database of Nihon Keizai Shimbun. Panel B shows the same statistics for the earlier period, October 1, 1987 to April 16, 1989, using data from the same source. In order to assess the reliability of our data, we compare the summary statistics for the NEEDS data with those based on data from another source, Data Resources Inc.(DRI). Panel $\mathrm{C}$ provides the same information as panel A, but based on DRI data. The difference between the two sets of data is due to the fact that the NEEDS data are recorded at the closing time of the Tokyo market, while the DRI data are at the closing time of the New York market on the same day. Panel D provides the same summary statistics for the U.S. dollar interest rate swap market, based on DRI data.

A comparison of panels $\mathrm{A}$ and $\mathrm{B}$ shows that the bid-offer spreads for swaps of all maturities have been declining over time. During the early 90's, the average bid-offer spread was about 3 basis points, which is roughly 2 basis points smaller than that in the earlier period. A similar comparison of panels $\mathrm{A}$ and $\mathrm{C}$ indicates that the spreads in the Tokyo market are roughly the same as those in the New York market. This is somewhat surprising because most of the information incorporated into the yen swap quotes is released during Tokyo business hours. Also, since the size of the yen swap market is much larger in Tokyo than in New York, we expected tighter spreads in the Tokyo market, due to the greater liquidity. Overall, although the two data sets are broadly similar in terms of the mid-rate, the NEEDS data are probably more reliable for our purpose, since they are also synchronous with the default-free JGB market, which is used as a reference for pricing purposes in the analysis that follows.

As can be seen from a comparison of panels A and D, the bid-offer spreads in the yen interest rate swap market are generally higher than those in the dollar interest rate swap market, perhaps indicating lower liquidity and trading volume in the yen market, as well as the lower credit quality of Japanese counterparties in the nineties. Another feature of the dollar data is that the spreads are fairly constant across maturities, indicating good liquidity across maturities. In contrast, in the yen market, the spreads increase roughly with 
maturity, indicating better liquidity at the short end. The average spread of yen interest rate swaps in the nineties is about the same as the spread for the A-rated dealer in dollar interest rate swaps in the study by Sun, Sundaresan and Wang (1993), based on data from the late eighties.

\section{Estimation of the term structure of interest rates in Japan}

In the absence of factors such as default risk, tax and liquidity, swap rates should be equal to the yields on par default-free JGBs with the same maturity. These frictions cause the actual swap rates to be quoted at a spread to the JGB yields for the same tenor, based on bonds priced at par. In this section, we discuss the methods we use for estimating the yields implied by the default-free JGBs. These yields are then compared to those implied by market swap rates in the next section. There are two common measures of the term structure of yields in the market. The first is based on the yield to maturity of coupon bonds priced at par and the second is based on the implied yields of zero-coupon bonds or the spot rates for different tenors. Since a coupon bond is a combination of several cash flows, its yield to maturity can be thought of as a weighted average of the spot rates. These two measures translate into two alternative ways of defining the spread between the JGBs and the swap rates: the yield basis and the spot rate basis. The first measure of the spread ("the yield spread") is the difference between the market swap rate and the yield on a par JGB of the same maturity. ${ }^{16}$ The second measure, also used by Duffie and Singleton (1997), is the spread between the implied spot rates from the swap quotes and the JGB prices ("the spot rate spread") and is computed for different maturities. We analyze the data using both measures.

In order to estimate the par JGB yields from market data, the first step is to compute the spot rates (or, equivalently, the discount functions they imply) for various maturities. Then, these rates can be used to compute the coupon on a synthetic bond for each maturity that would trade at par. The yield on such a bond is defined as the par bond yield. Thus, the estimated spot rates are used directly, to compute the spot spread, and indirectly, to compute the yield spread. In this section, we discuss the methods we use to estimate the spot rates, and indirectly, the par bond yields of the JGBs.

In a world without taxes, liquidity effects and other frictions, the price of a bond is the present value of the promised cash flows:

\footnotetext{
${ }^{16}$ This is a more precise version of the commonly-used market quotation based on spreads relative to on-the-run Treasury bonds of the same maturity. The difference is that in our estimation, the Treasury yield is based on a bond priced exactly at par, rather than a liquid bond of the same tenor. Empirically, this difference may be significant relative to the spread we are measuring, since the on-the-run bonds may be priced away from par, if the yield curve has shifted significantly since the bond was issued.
} 


$$
\begin{aligned}
P_{j}\left(t, t+M_{j}\right) & =\sum_{m=1}^{M_{j}} c_{j m} \exp \left(-i^{T}(t, t+m) m\right)+F_{j} \exp \left(-i^{T}\left(t, t+M_{j}\right) M_{j}\right) \\
& =\sum_{m=1}^{M_{j}} c_{j m} D(t, t+m)+F_{j} D\left(t, t+M_{j}\right)
\end{aligned}
$$

where $P_{j}\left(t, t+M_{j}\right)$ is the price at time $t$ of bond $j$ with a maturity $M_{j}, c_{j m}$ its coupon at time $m, m=1,2, \ldots, M_{j}$, and $F_{j}$ its face value paid at $M_{j}$. The continuously compounded spot interest rate between time $t$ and $t+m$ is defined as $i^{T}(t, t+m)$. The discount or present value function is defined by $D(t, t+m)=\exp \left(-i^{T}(t, t+m) m\right)$. Hence, the term structure of interest rates at time $t$ can be described by the present value function, or equivalently, the vector of spot interest rates (or forward interest rates).

For the estimation of the term structure of interest rates in the JGB market, we use the cubic B-spline method, a modification of the method proposed by McCulloch (1975). The motivation for this modification of the cubic-spline method is the finding by Shea (1984) that some spline bases, such as those chosen by McCulloch (1975), can result in inaccuracies due to a nearly perfectly collinear regressor matrix. Overall, the cubic B-spline method yields reasonable estimates of the term structure of the JGBs. The mean of the absolute fitted price error in the JGB market is 11 basis points which is somewhat higher than the errors found in comparable studies in the U.S. Treasury bond market. It is interesting to note that in spite of the greater importance of liquidity and coupon effects in the JGB market, the absolute fitted price error in the JGB market is not all that different from the U.S. Treasury bond market. ${ }^{17}$

As modeled by Duffie and Huang (1996) and Duffie and Singleton (1997), the price of a risky zero-coupon bond can be modeled in an arbitrage-free framework based on the shortterm risk-adjusted interest rate process for defaultable assets such as swaps. ${ }^{18}$ The reduced form of such a model translates into the swap rate, $c^{S}\left(t, M_{j}\right)$, which is the coupon rate on the fixed side of the swap. Since the swap rate is the yield on a par coupon bond of the same maturity, it can be expressed in terms of the (zero-coupon) discount factors, for semi-annual payments, as follows:

$$
c^{S}\left(t, M_{j}\right)=2 \times \frac{1-S\left(t, t+M_{j}\right)}{\sum_{m=1}^{2 M_{j}} S(t, t+0.5 m)} .
$$

where $S(t, t+0.5 m)$ is the discount factor at time $t$ for maturity $t+0.5 m$ and $M_{j}$ is the maturity of the swap. The discount function can be related to the implied spot rates by:

\footnotetext{
${ }^{17}$ More detailed empirical results on non-present value factors in the JGB market are presented in Eom, Subrahmanyam and Uno (1998).

${ }^{18}$ In Duffie and Singleton (1997), the short-term risk-adjusted interest rate process for defaultable assets is affected by the short-term interest rate process for non-defaultable assets, the convenience yield that allows for the effect of differences in liquidity between the government and swap markets, a "risk-neutral" hazard rate of the default event, and the fractional loss of market value given default.
} 


$$
S(t, t+m)=\exp \left(-i^{S}(t, t+m) m\right), m=0.5,1, \ldots, M_{j} .
$$

where $i^{S}(t, t+m)$ is the spot rate implied by the swap rates at time $t$ for maturity $t+\tau$, equivalent to the discount factor, $S(t, t+m)$.

In our estimation of the implied spot rates, we use six rates with a maturity of less than or equal to one year (one-, two-, three-, six- and twelve month TIBOR rates) and the mid-points of six swap rates (two-,three-,four-, five, seven-, and ten year maturities). Since only twelve rates are available for each date, it is necessary to use a parsimonious estimation method. We adopt the extended Nelson and Siegel (1987) method for the estimation of the spot rates implied by the yen swap market, for which, following Svensson (1994), we assume that

$$
i^{S}(t, t+m)=\left[\begin{array}{c}
\beta_{0}+\beta_{1} \frac{1-\exp \left(-\frac{m}{\delta_{1}}\right)}{\frac{m}{\delta_{1}}}+\beta_{2}\left[\frac{1-\exp \left(-\frac{m}{\delta_{1}}\right)}{\frac{m}{\delta_{1}}}-\exp \left(-\frac{m}{\delta_{1}}\right)\right] \\
+\beta_{3}\left[\frac{1-\exp \left(-\frac{m}{\delta_{2}}\right)}{\frac{m}{\delta_{2}}}-\exp \left(-\frac{m}{\delta_{2}}\right)\right]
\end{array}\right]
$$

This specification implies that there exists a smooth instantaneous forward rate curve with a flat asymptote. It is also model-free and can generate yield curves with a desirable range of shapes, including upward-sloping, inverted and hump-shaped. For each date $t$, we estimate $\left\{\beta_{0}, \beta_{1}, \beta_{2}, \beta_{3}, \delta_{1}, \delta_{2}\right\}$ to minimize the mean-squared error between the observed swap rates and the fitted swap rates, $c^{S}\left(t, M_{j}\right)$ for all maturities up to ten years, implied by the above equation.

Table 3 reports the summary statistics of the fitting errors for yen swaps. The fitted values are obtained by estimating the extended Nelson and Siegel method, using the midpoints of six swap rates and six TIBOR rates. The fitting errors are the absolute differences between actual swap rates and the fitted values. The table shows that the mean fitting error is of the order of 2 basis points with a standard deviation of 2 basis points, indicating that the extended Nelson and Siegel produces a reasonably good fit of yen swap rates.

\section{Credit risk in the yen swap market: empirical results}

In this section we report the main results of our analysis. We first analyze the distributional characteristics of the implied spot rates in the yen swap market. We then examine the specification of the processes for the spot interest rate and the swap spread using a generalized method of moments (GMM) analysis. We estimate the term structure of swap spreads and analyze the spot rates from the swap market in relation to those in the comparable JGB market. Next, we study the interest rate and credit risk factors that explain the swap 
spreads. Finally, we present some results on the relation between the yen swap spreads and the comparable spreads in the dollar swap market.

\subsection{Implied spot rates in the JGB and yen interest rate swap market}

In this subsection, we examine the distributional features of the spot rates implied in the default-free bond markets and the swap market. Table 4 provides the summary statistics of the implied spot rates estimated from the JGBs and swap markets respectively. Panel A in the table provides the statistics in terms of the levels of the rates and panel $\mathrm{B}$ in terms of first differences of the spot rates estimated from JGB yields. Panels C and D also provide the corresponding statistics for the spot rates estimated from the swap rates.

There are several noticeable differences between the distributional features of the implied spot rates in the two markets. The spot rate implied by the swap rates, $i^{S}(t, t+m)$, is defined as the sum of the spot rate implied by the yields of the non-defaultable bonds, $i^{T}(t, t+m)$, and the component, $\pi(t, t+m)$, due to credit risk and/or liquidity factors, i.e.,

$$
i^{S}(t, t+m)=i^{T}(t, t+m)+\pi(t, t+m)
$$

Surprisingly, the volatilities of the longer term spot rates implied by the swap rates are less than those implied by the JGB yields of the same maturity. This implies that the covariance between the default-free rates and the swap spread is negative. ${ }^{19}$ In fact, back-of-the-envelope calculations show that the correlation between the default-free rates and the swap spread gets more negative with maturity. This pattern also applies to the first-differenced series of the spot rates. Detailed models of swap pricing incorporating credit/liquidity effects would have to take this correlation into account.

Another feature of the data pertaining to the spot rates from the two markets is that both rates show a mean-reverting behavior and the term structure of autocorrelations of the first-differenced series is declining for longer maturities. However, the autocorrelation coefficients of the implied spot rates from JGBs are noticeably higher than those from swaps.

To better understand the behavior of the spot rates and the swap spreads, we perform a GMM test based on the assumption that both the changes in the spot rates of the JGBs as well as the changes in the spreads follow AR(1) processes. We test the lognormality of the default-free spot rates and the spread, as well as correlations between the two rates. Specifically, we model the spot interest rate of JGBs as

$$
\Delta i^{T}(t, t+m)=\alpha(m)+\beta(m) \Delta i^{T}(t-1, t-1+m)+\sigma(m) \varepsilon_{t}
$$

and the changes in the swap spread as

$$
\Delta \pi(t, t+m)=\theta(m)+\lambda(m) \Delta \pi(t-1, t-1+m)+\delta(m) \eta_{t}
$$

\footnotetext{
${ }^{19}$ The necessary condition for $\operatorname{Var}\left(i^{T}(t, t+m)\right)>\operatorname{Var}\left(i^{S}(t, t+m)\right)$ is $\operatorname{Cov}\left(i^{T}(t, t+m), \pi(t, t+m)\right)<0$.
} 
where $\varepsilon_{t}$ and $\eta_{t}$ are $i, i, d$ standard normal variables and $E\left[\varepsilon_{t} \eta_{t}\right]=\rho(m)$. We estimate the seven parameters of interest (the three coefficients in each equation plus the correlation between the two errors) by matching two sets of unconditional moments of the data, the mean, standard deviation, skewness, kurtosis and autocorrelation, as well as the correlation between $\Delta i^{T}(t, t+m)$ and $\Delta \pi(t, t+m)$ (a total of eleven moment conditions). Namely, we use 11 moment conditions for the parameter model so that we can test the normality assumption. The variance-covariance matrix is estimated by the Newey-West method with 15 lags.

Table 5 provides the estimation results for the specifications of the processes. $\chi^{2}(4)$ is a J-statistic that tests the normality specification. Notably, the assumption of normality for both processes is rejected at the five percent significance level for three maturities and at the ten percent significance level for the other three maturities. Given that the GMM specification test using unconditional moments has low power to begin with, the rejection of normality of the first-differences (lognormality) should be taken seriously. The results suggest that swap pricing models and related models for derivatives such as swaptions built on the assumption of lognormality of swap rates may be mis-specified.

Apart from the rejection of lognormal swap rates, Table 5 provides other parameter estimates of interest, although the results indicate that a simple-minded two-factor lognormal model may not work for pricing. Note that the estimates of the correlation coefficient between the changes in the default-free spot rates and the spread, $\rho$, are negative for all maturities and statistically significant for four-, five-, seven-, and ten-year spot rates. The $\rho$ estimates for seven- and ten-year spot rates are highly negative at -0.43445 and -0.47727 , respectively. If the swap spreads reflect the default risk in the economy, these strong negative correlations for longer maturities indicate that the default risk spread is counter-cyclical.

The parameter estimates in Table 5 also indicate that the mean-reversion of the swap rates is mostly driven by the mean-reversion of non-defaultable interest rates. The meanreversion parameters of non-defaultable spot rates, $\beta$, are significant for up to five year maturities. The mean-reversion parameters of the swap spot spreads, $\lambda$, are negative for all maturities and the statistical significance increases with maturity. However, the negative autocorrelation of the changes in the spreads may be induced by over-differencing the series.

\subsection{Tests of the yen interest rate swap spreads}

We next analyze the spreads of yen interest rate swaps over the corresponding default-free rates measured in the two ways defined earlier: the yield basis and the spot basis. Figure 2 presents the two- and ten-year yen swap spreads on the yield basis i.e., the difference between the yen swap rates and the par bond yields of JGBs with the corresponding maturity. Par bond yields are based on the spot rates estimated from off-the-run JGBs, as discussed in the section 4. The swap yields are the mid-points of bid-offer swap rates. As the graph shows, the two swap spreads moved together during most of the sample period. These two 
swap spreads, however, behaved somewhat differently for the period that the swap curve was inverted. Notice that the estimated swap spreads were positive in most of the sample period, but we do find negative spreads in a few cases. Of 317 observations, $3.8 \%$ and $1.6 \%$ of the estimated swap spreads are negative for the two- and ten-year maturities, respectively.

Panel A of Table 6 also provides the mean, standard deviation and the autocorrelation coefficient for the yen swap spreads on the yield basis for various maturities based on the term structures estimated in section 4. Panel B provides the same statistics for the yen swap spreads in terms of spot rates (the difference between the implied spot rates from swaps and the implied spot rates from the JGBs). Panel $\mathrm{C}$ reports the means, standard deviations and autocorrelation coefficients for the spreads in the U.S. dollar interest rate swap market, based on data obtained from the DRI database.

Figure 3 presents the spreads of the yen interest rate swaps and the U.S. dollar interest rate swaps. As Figure 3 shows, the average spreads of yen interest rate swaps, in terms of yields, as a function of maturity, show a humped shape. This humped pattern of spreads is also present for spreads on a spot rate basis. The humped shape of yen interest rate swap spreads is strikingly different from the pattern in the dollar interest rate swap market. As in the case of the yen swap yield spreads, the average swap spread for U.S. dollar swaps is defined as the difference between the swap rates and the par bond yields, based on the constant maturity Treasury yields. As shown in Panel C, for the same period, the spreads of dollar interest rate swaps increase monotonically with the maturity of the swap.

The humped shape of yen interest rate swap spread is also very much different from the empirical pattern of the corporate bond spreads in the US as documented by Sarig and Warga (1989) and Fons (1994). They find that the average credit yield spread for investment-grade firms is upward-sloping with maturity, while the credit yield spread is humped or inverted for speculative-grade firms. A recent paper by Helwege and Turner (1999), however, finds that the credit yield spread is, on average, upward-sloping even for BB- or B-rated firms when the sample selection bias problem is corrected.

There are several reasons why the pattern of spreads of yen interest rate swaps differs from that of dollar interest rate swaps. First, the long-end of the JGB yields may be downward biased due to the liquidity premium, since a significant proportion of trading in JGBs is concentrated in the benchmark issue. Even the "old benchmark" long-term bonds may be relatively more liquid than the middle range of the term structure. However, the measurement bias in the long-term spot rates due to better liquidity of the "old benchmark" bonds works against the inverted U-shape. If the "old benchmark" bonds are more liquid, then yields of the long-term segment should be lower than what they would be without the liquidity effect. If the long-term spot rates are under-estimated due to the liquidity effect, then swap spreads (swap spot - JGB spot) are upwardly biased. Thus, the true spread curve would be even more inverted. Second, the segmentation between the short-end and long-end may be another explanation for the inverted U-shape. For example, if the credit risk premium for long-term corporate bonds in Japan is comparatively lower than for short- 
term borrowing, the short-term borrower can use swaps to finance at the long-term fixed rate and swap it into a short-term floating basis. Thus, since the long-term corporate bonds cannot be shorted very easily, the swap rates are reduced due to the demand for receive-fixed, pay-floating swaps. Third, as shown in the previous section, the swap spread is negatively correlated with the default-free interest rates. This is consistent with Longstaff and Schwartz (1995) who present a model for coupon bonds in which firm value is correlated with the riskfree rate. In their model, the credit yield curve may be upward sloping or hump-shaped and the peak spread for the hump-shaped curve occurs at the third year.

To provide further evidence on the relation between the default-free bonds and swaps, we regress the implied par bond yields from JGBs on the swap rates of the corresponding maturities:

$$
S W(t, t+m)=\alpha(m)+\beta(m) P A R(t, t+m)+\epsilon .
$$

Panel A of Table 7 presents the results of the regression. If swap rates move one-to-one with par yields of the JGBs, $\beta(m)$ should be one and $\alpha(m)$ should also be zero. The point estimates of $\beta(m)$ for yen interest rate swaps are close to one indicating that swap rates move closely with JGB par yields. However, this implication may be misleading since the regressor and the regressand are highly autocorrelated and hence, the point estimates of $\beta(m)$ as well as the $\mathrm{R}^{2}$ may be upward-biased.

Hence, we also presents the regression results of the first-differences of the implied par bond yields on the first-differences of the swap rates of the corresponding maturities:

$$
\Delta S W(t, t+m)=\alpha(m)+\beta(m) \Delta P A R(t, t+m)+\nu .
$$

We test the null hypothesis that $\beta(m)=1$ and $\alpha(m)=0$ and the null hypothesis that $\beta(m)=1$. In estimating the regression and testing the two hypotheses, there are two econometric issues that should be dealt with caution. First, although we use first differences, the errors of the regression may be still autocorrelated and heteroscedastic. To address this problem, we use the heteroscedasticity and autocorrelation-consistent (HAC) estimate of the covariance matrix with six lags. The other issue is that the regression is subject to the "estimated regressor" problem, which arises from the fact that the true par yields of the JGBs are measured with error, and hence, the least squares estimator results in an inconsistent and biased estimate. To gauge the potential bias due to the measurement error, we also report the results using instrumental variable estimation with the instruments being the lagged regressor and lagged spreads between the TIBOR and Gensaki rates. Standard errors and test statistics are also based on the HAC covariance estimate with six lags.

Panel B of Table 7 presents the least square estimation results of the null hypothesis that $\beta(m)=1$ and $\alpha(m)=0$. The null hypothesis can be rejected at the 5 percent significance level for all maturities except two-years. The null hypothesis that $\beta(m)=1$ can be rejected at the 5 percent significance level for all maturities. Even though the hypothesis that $\beta(m)=1$ is rejected, the point estimates of $\beta(m)$ for two to five-year swaps are larger than 0.9. Also, more than $70 \%$ of variations of the changes in swap rates can be explained by the changes in the JGB par bond yields. 
Panel $\mathrm{C}$ of Table 7 presents the results of the instrumental variable regression for the two null hypothesis that $\beta(m)=1$ and $\alpha(m)=0$. Unlike the case of the ordinary least squares estimation, both hypotheses cannot be rejected for all maturities except the two-year swap. The patterns of the point estimates of $\beta(m)$ are also different from the least squares estimation. The point estimates of $\beta(m)$ for four- to ten-year swaps are very close to one. These results indicate that the previous results are subject to bias due to measurement errors. We can conclude that the changes in the swap rates have almost a one-to-one relationship with changes in the par bond yields. ${ }^{20}$

\subsection{Interest Rate Factors and Credit Spreads}

In this subsection, we analyze the relation between interest rate factors and the swap spreads. As mentioned in the previous section, swap spreads are usually negatively related to the corresponding default-free interest rates, and the negative relation is stronger for swaps of longer maturities. To better understand the impact of interest rate factors on the swap spreads, we decompose the movements of interest rates into factors that explain the defaultfree term structure.

As shown in studies of the U.S. Treasury bond market such as Andersen and Lund (1996), Balduzzi and Eom (1998) and Litterman and Scheinkman (1991), the level, slope and curvature of the yield curve explain most of the time series variations of yield movements. Singleton (1994) also finds that these three factors are important for the JGB market. In addition to these three factors that explain the movements in the default-free term structure, other factors have an important role in swap pricing. For example, as discussed in section 3 and shown by Duffie and Huang (1996) and Mozumdar (1996), when the credit quality of the counterparties of a swap is asymmetric, the swap rate is negatively related to the slope of the yield curve. This is because of the possibility of default by the counterparty for whom the swap is out-of-the-money (i.e., has negative value) to the counterparty for whom the swap is in-the-money (i.e., has positive value). Additionally, as pointed out by Friedman and Kuttner (1993) and Estrella and Mishkin (1998), the slope of the term structure is procyclical, but the default spread shows counter-cyclical behavior over the U.S. business cycle. Thus, swap spreads may be negatively related to the slope of interest rates due to expected future economic growth.

The level and the curvature of the term structure of default-free rates are also important when the credit quality of the counterparties is asymmetric. As argued by Sorensen and Bollier (1994), swap counterparties own a series of European-style options, exercisable when they default on their payments. They argue that the swap rate should be negatively related to the level of interest rates and positively to the curvature factor which is a proxy for volatility.

\footnotetext{
${ }^{20}$ This conclusion is in contrast to the conclusion in Minton (1997), who finds that the relationship is less than one-to-one in the dollar swap market.
} 
Apart from interest rate factors, we use the spread between three-month TIBOR and three-month Gensaki rates as a measure of the short-term default risk of corporate issuers. To measure the default spread for long-term bonds, we use the yields on corporate bonds issued by the Tokyo Electric Company. Due to limited availability of data for these yields, we perform the following regression for the sample period January 6, 1992 to May 17, 1996, consisting of a 227 week sample.;

$\Delta S W S P_{t}(m)=\beta_{0}+\beta_{1} \Delta r_{3, t}+\beta_{2} \Delta$ Slope $_{t}(m)+\beta_{3} \Delta$ Curve $_{t}+\beta_{4} \Delta T E D_{t}+\beta_{5} \Delta C Y$ ield $d_{t}+\varepsilon_{t}$

where $\Delta S W S P_{t}(m)$ denotes the change in the swap spread of maturity $m$-year, $\Delta r_{3, t}$ the change in the three-month Gensaki rate, Slope $_{t}(m)$ the difference between the $m$-year JGB spot rate and the 1 year JGB spot rate, $\Delta$ Curve $_{t}$ the change in the curvature factor measured by (ten- year JGB spot rate + three month Gensaki rate) $/ 2$ - the one-year spot rate, $\Delta T E D_{t}$ the difference between the three-month TIBOR rate and the three month Gensaki rate, and $\Delta C$ Y ield $t_{t}$ the change in the yield of 12 year Tokyo Electric Company corporate bond.

Panel A of Table 8 presents the regression results for the changes in the yen interest rate swap spreads of different maturities measured on a yield basis. Among the explanatory variables, the change in the slope of the JGB term structure has a significant negative impact on the change in the swap spreads. In other words, when the yield curve slope steepens, the swap spread decreases. The point estimates for the slope factor also shows that the ten year swap spreads increase more than medium maturity swaps as the slope of the JGB curve decreases. The curvature factor also has a significant relationship with the swap spreads. If the concavity increases, swap spreads in general increase, but more so for the mediumterm swaps. Overall, the empirical results for interest rate factors in the JGB market are consistent with Dai and Singleton (1997). They also find that the level, slope and curvature are significant explanatory factors for dollar swap rates.

Two measures of default risk are also significantly and positively related to changes in the swap spreads. For example, a 100 basis point increase in corporate bond yield is accompanied by a 34 basis point increase in ten-year swap spread. ${ }^{21}$ When the changes in the spread of the corporate bond yield over par yield of JGBs is used in the regression, an increase of 100 basis points in yield spread of corporate bond over JGBs results in 24 basis points increase in ten-year swap spread. In the case of dollar interest rate swaps, Minton (1997) finds that a 100 basis point increase in corporate bond spread over ten-year treasury yield results in about a 15 basis point increase in ten-year swap spread. The empirical results herein are rather inconsistent with the view that the long-term yen swap rates may be inefficiently priced because of the pricing insensitivity of the Japanese yen corporate bonds with respect to default risk. However, the results are consistent with theoretical models of Duffie and Huang (1996) and Li (1998), who suggest that swap rates should not change one for one with respect to the change in default premium of corporate bonds due to the difference in contractual features of swaps and corporate bonds. However, the yen swap spreads are more

${ }^{21}$ To avoid potential non-linearity effects due to the choice of the yield basis, we also perform the same analysis with swap spreads measured on a spot basis. The results are reported in the Panel B of Table 8 . The results are very similar to those for the spreads measured on a yield basis. 
sensitive to the default premium of corporate bonds than the calibration results of existing models suggest, indicating that credit enhancement devices in the yen swap market may not adequately reduce the counterparty risk.

\subsection{The international linkage of yen swap spreads}

We analyze next the relationship between swap spreads denominated in yen compared with those in the other major currency, the U.S. dollar. Table 9 presents the correlation coefficients between the changes in the yen interest rate swap spreads, the changes in the dollar interest rate swap spreads, estimated above, and the changes in the interest rate differentials between U.S. and Japan. The interest rate differentials are based on the constant maturity yields of government bonds of the same maturities with swaps. Again, to avoid spurious correlation, we analyze the correlations for changes in these variables and not their levels.

Given the increasing globalization of trade and finance, we would expect that international capital markets are fully integrated. Thus, if swap spreads mainly reflect the counterparty risk and/or default risk of large corporate issuers with global operations, the credit risk should be, at least to some extent, a global factor. Hence, swap spreads in yen and dollars should be highly correlated. However, the actual correlations between swap spreads in yen versus dollar interest rates swaps are surprisingly low. For example, the correlation for two-year swaps is negligible at -0.00476 . Even for seven-year swaps, the correlation is only 0.12394 , somewhat larger than for other maturities.

The changes in the spreads for yen interest rate swaps are more correlated with the changes in the interest rate differentials. For example, the correlation between the ten-year yen interest rate swap spread and the interest rate differential, which is defined as the tenyear U.S. government par bond yield minus ten-year JGB par bond yield, is 0.45 . For other maturities, the correlation ranges from 0.26 to 0.38 . The change in the spread of dollar interest rate swaps is also correlated with the change in the interest rate differential, but the magnitude is less than one-third of that for yen interest rate swaps. A possible explanation for the high correlation between the yen interest rate swap spread and the interest rate differential is that arbitrageurs go long yen interest rate swaps and go short dollar interest rate swaps to construct a spread position between the Treasury bonds (usually in the respective futures contracts) in the two countries. Such a spread is constructed to take advantage of the differential between the low long-term yields of JGBs and the high long term yields of U.S. Treasury bonds. Hence, the yen swap rate is higher due to the demand for pay-fixed yen swaps.

To analyze the relation between the two interest rate swaps further, the changes in the yen interest rate swap spreads are regressed on (1) their own lagged values, (2) the lagged changes in the dollar interest rate swap spreads, and (3) the lagged changes of the interest differentials between U.S. and Japan. The results are reported in Panel A of Table 10. Panel $\mathrm{B}$ of Table 10 presents the regression results for the changes in the dollar interest rate swap 
spreads in terms of the lagged variables.

In the case of yen interest rate swaps, the lagged changes in the spreads for dollar interest rate swaps "Granger-cause" the increase in spreads of yen interest rate swaps for the twoand three-year maturities. However, the causality does not run the other way. For the case of dollar interest rate swaps, the lagged changes of spreads in the yen interest rate swaps do not have the same impact on the spreads in dollar interest rate swaps for all maturities. Thus, for the short-end of the swap curve there are spill-over effects from the changes of spreads in dollar interest rate swaps to the yen interest rate swap market.

More importantly, the lagged changes of interest differentials Granger-cause the increase in the spreads of yen interest rate swaps for most maturities except for the three year swap. However, the lagged changes in the interest rate differentials Granger-cause the increase in spreads of dollar interest rate swaps only for two-year swaps. These results are consistent with the hypothesis that yen interest rate swaps are used as a part of spread position created due to market frictions in the JGB market, e.g., the difficulty in shorting JGBs. Hence, the demand for swaps induced by such frictions may have an impact on the swap rates. The broad conclusion may be that although credit risk is priced in the dollar and yen markets, the credit risk factor is currency/country specific rather than global in nature.

\section{Conclusion}

The fixed rate for interest rate swaps, or the swap rate, is closely related to the yield on a par default-free bond of the same maturity. In addition, other factors such as credit risk and liquidity effects play a role in explaining the spread between these two rates. The spread between the rates, or the swap spread, is of interest to researchers and practitioners alike. From both perspectives, the spread may be used as the market's measurement of the average counterparty credit risk as well as frictional effects in the fixed income markets, to address a wide range of questions such as the business cycle effects of credit risk and the efficiency of hedges based on derivative instruments.

Our analysis based on data from the nineties in the yen JGBs and interest rate swap markets indicates that it is possible to closely fit the term structure of default-free rates and swap rates using polynomial methods. Our empirical results show 1) that the swap spread in the yen market displays an inverted U-shape, in contrast to the dollar market where it rises monotonically, 2) that the shocks in the yen swap spread are negatively correlated with the shocks in the default-free spot rates, especially for longer maturities and 3) that the commonly-used assumption of lognormal default-free interest rates and swap spreads is strongly rejected by the data. These empirical findings should be taken into account in modeling interest rate derivatives such as caps, floors and swaptions, and may help in calibrating the "smile" effect of the implied volatility in these markets. 
The results also indicate that the yen swap spread is only weakly linked to the dollar swap spread, although there are indications of causality, especially at the short end, from the dollar market to the yen market. The swap spread may be also influenced by arbitrage activity. During the period under study, we find that the long-term yield differential between Japanese and U.S. Treasury markets has a significant impact on the demand for pay-fixed yen interest rate swaps.

The credit risk factor influencing the swap spread can be broken down into two elements. The first factor is the impact of the default-option that should be priced in the swap rate. The other is the credit risk at the short and long ends of the maturity structure. The first factor is seen to be strongly influenced by the level, slope and maturity of the default-free term structure. Even though data were available only for a relatively crude proxy of the credit risk for the long term bonds, we are able to discern its impact on the swap spread. Surprisingly, however, the short term measure of credit risk has a weak effect on the credit spreads. In future work, we hope to study this issue in greater detail. 
Credit Risk and the Yen Interest Rate Swap Market ...................... 23

\section{References}

Andersen, T. G., and J. Lund, 1996, "Stochastic volatility and mean drift in the short term interest rate diffusion: sources of steepness, level and curvature in the yield curve", Working paper, Northwestern University.

Balduzzi. P., and Y. H. Eom, (1998), "Nonlinearities in U.S. treasury yields: a seminonparametric approach," mimeo.

Boudoukh, J. and R. F. Whitelaw, 1993, "Liquidity as a choice variable: a lesson from the Japanese government bond market," it Review of Financial Studies, 6, 265-292.

Brown, K., W. V. Harlow, and D. J. Smith, 1994, "An empirical analysis of interest rate swap spreads," Journal of Fixed Income, 3, 61-68.

Cox, J., J. Ingersoll and S. Ross, 1985, "A theory of the term structure of interest rates," Econometrica, 53, 385-407.

Dai, Q., and K. J. Singleton, 1997, "Specification analysis of affine term structure models," Working Paper, National Bureau of Economic Research.

Duffie, D., 1996, "Special repo rates," Journal of Finance, 51, 493-526.

Duffie, D., and M. Huang, 1996, "Swap rates and credit quality," Journal of Finance, 51, 921-949.

Duffie, D., and K. Singleton, 1997, "An econometric model of the term structure of interest-rate swap yields," Journal of Finance, 52, 1287-1321.

Eom, Y. H., M. G. Subrahmanyam and J. Uno, 1998, "Coupon effects and the pricing of Japanese government bonds: an empirical analysis," The Journal of Fixed Income, 8, 69-86.

Elton, E. J., and C. Green, 1998, "Tax and liquidity effects in pricing government bonds," Journal of Finance, v53, 1533-1562.

Estrella, A. and F. S. Mishkin, 1998, "Predicting U.S. recession: financial variables as leading indicators," it Review of Economic Studies, v80, 45-61.

Fons, J., 1994 "Using default rates to model the term structure of credit risk," it Financial Analysts Journal, 50, 25-32.

Friedman, B. and K. Kuttner, 1993, "Why does the paper-bill spread predict real economic activity?," in James Stock and Mark W. Watson (eds), Business Cycles, Indicators, and Forecasting, University of Chicago Press, 213-253.

Grinblatt, M, 1995, "An analytic solution for interest-rate swap spreads," Working paper, 
UCLA, Anderson Graduate School of Management.

Gupta, A. and M. G. Subrahmanyam, 2000, "An empirical examination of the convexity bias in the pricing of interest rate swaps," Journal of Financial Economics, 55, 239-279.

Hamano, M., 1997, "Empirical study of the yen interest rate swap spread," Gendai Finance (Modern Finance), 1, 55-67.

Helwege, J. and C. M. Turner, 1999, "The slope of the credit yield curve for speculativegrade issuers," Journal of Finance, 54, 1869-1884.

Huge, B. and D. Lando, 2000, "Swap pricing with two-sided default risk in a rating-based model," Working paper, University of Copenhagen.

Jarrow, R. and S. Turnbull, 1995, "Pricing options on financial securities subject to default risk," Journal of Finance, 50, 53-86.

Jarrow, R. and S. Turnbull, 1997, "When swaps are dropped," Risk, 10, 70-75.

Koticha, A., 1993, "Do swap rates reflect default risk?" Unpublished Ph.D. Dissertation, New York University.

Li, H., 1998, "Pricing of swaps with default risk," Review of Derivative Research, 2, 231-250.

Litterman, R. and J. Scheinkman (1991), "Common factors affecting bond returns," Journal of Fixed Income, 47, 129-1282.

Litzenberger, R. H., 1992, "Swaps: plain and fanciful," Journal of Finance, 47, 597-620.

Longstaff, F. and E. S. Schwartz, 1995, "A simple approach to valuing risky fixed and floating rate debt," Journal of Finance, 50, 811-830.

McCulloch, J. H., 1971, "Measuring the term structure of interest rates," Journal of Business, 44, 19-31.

McCulloch, J.H., 1975, "The Tax-adjusted yield curve," Journal of Finance, 30, 811-829.

Merton, R., 1974, "On the pricing of corporate debt: the risk structure of interest rates," Journal of Finance, 29, 449-470.

Minton, B., 1997, "An empirical examination of basic valuation models for plain vanilla U.S. interest rate swaps," Journal of Financial Economics 44, 251-277.

Mozumdar, A., 1996, "Essays on swaps and default risk," Ph.D. Dissertation, Stern School of Business, New York University, 1996. 
Credit Risk and the Yen Interest Rate Swap Market ...................... 25

Nelson, C.R. and A.F. Siegel, 1987, "Parsimonious modeling of yield curves," Journal of Business, 60, 473-489.

Sarig, O. and A. Warga, 1989, "Some empirical estimates of the risk structure of interest rates," Journal of Finance, v44, 1351-1360.

Shea, G. S., 1984, "Pitfalls in smoothing interest rate term structure data: equilibrium models and spline approximations ," Journal of Financial and Quantitative Analysis, 19, 253-69.

Singleton, K., 1994, "Yield Curve Risk in Japanese Government Bond Markets," Japanese Journal of Financial Economics, 1, 5-32.

Sorensen, E. H. and T. F. Bollier, 1994, "Pricing swap default risk," Financial Analysts Journal, 50, 23-33.

Sun, T., S. Sundaresan and C. Wang, 1993, "Interest rate swaps: an empirical investigation," Journal of Financial Economics, 34, 77-99.

Svensson, L. E.O., 1994, "Estimating and interpreting forward interest rates: Sweden 1992-1994," Centre for Economic Policy Research, Discussion Paper 1051. 
Credit Risk and the Yen Interest Rate Swap Market ...................... 26

\section{Table 1. Summary Statistics of Yen Swap Rate}

Panel A provides the mean, standard deviation, skewness, kurtosis and autocorrelation coefficient for yen swap rates at the market close (about 5 P.M., Tokyo time) for swaps of maturities from two years to ten years for the period April 27, 1990 to May 17, 1996. The number of observations is 1497. The quotations, based on the daily mid-rates for the market recorded at 5 p.m., were obtained from the NEEDS database of Nihon Keizai Shimbun. Panel B provides the same summary statistics for the first differences of the swap rates.

Panel A: Level

\begin{tabular}{||c|c|c|c|c|c||}
\hline \hline Maturity & MEAN & ST DEV & SKEWNESS & KURTOSIS & AUTO \\
\hline \hline 2 year & 4.13015 & 2.22892 & 0.40250 & -0.97343 & 0.99851 \\
\hline 3 year & 4.40113 & 2.03433 & 0.30921 & -0.98335 & 0.99850 \\
\hline 4 year & 4.63531 & 1.84528 & 0.22321 & -0.99537 & 0.99844 \\
\hline 5 year & 4.81195 & 1.70434 & 0.21066 & -0.99432 & 0.99839 \\
\hline 7 year & 5.04854 & 1.46320 & 0.17914 & -0.98398 & 0.99823 \\
\hline 10 year & 5.18545 & 1.33743 & 0.19221 & -0.98166 & 0.99814 \\
\hline \hline
\end{tabular}

Panel B: First Differences

\begin{tabular}{||c|c|c|c|c|c||}
\hline \hline Maturity & MEAN & ST DEV & SKEWNESS & KURTOSIS & AUTO \\
\hline \hline 2 year & -0.00399 & 0.05046 & 0.38481 & 4.68360 & 0.14908 \\
\hline 3 year & -0.00357 & 0.05214 & 0.61474 & 6.42400 & 0.15526 \\
\hline 4 year & -0.00322 & 0.05220 & 0.68201 & 5.98456 & 0.12745 \\
\hline 5 year & -0.00300 & 0.05038 & 0.50316 & 3.98756 & 0.11131 \\
\hline 7 year & -0.00265 & 0.04748 & 0.41260 & 2.36409 & 0.06076 \\
\hline 10 years & -0.00245 & 0.04580 & 0.37688 & 2.25389 & 0.02336 \\
\hline \hline
\end{tabular}


Credit Risk and the Yen Interest Rate Swap Market ..................... 27

Table 2. Summary Statistics of Bid-Offer Spreads

Panel A provides the means and standard deviation of the bid-offer spreads of the yen swap rates for swaps of maturities from two years to ten years for the period April 27,1990 to May 17, 1996. The quotations, based on the bids and offers at the close of the market recorded at around 5 P.M. Tokyo time, are obtained from the NEEDS database of Nihon Keizai Shimbun. Panel B provides the same summary statistics for the period 1987 to December 1989. Panel C also provides the summary statistics of the bid-offer spreads of the yen swap rates obtained from Data Resources Inc. Panel D provides the summary statistics of the bid-offer spreads of U.S. dollar swap rates also obtained from Data Resources Inc.

Panel A: NEEDS yen interest rate swap: April 1990-May 1996

\begin{tabular}{||c|c|c|c|c|c|c||}
\hline \hline Maturity & 2 year & 3 year & 4 year & 5 year & 7 year & 10 year \\
\hline MEAN & 0.02854 & 0.02807 & 0.03170 & 0.02815 & 0.03511 & 0.03768 \\
\hline ST DEV & 0.01114 & 0.01098 & 0.01126 & 0.01026 & 0.01176 & 0.01313 \\
\hline \hline
\end{tabular}

Panel B: NEEDS yen interest rate swap: October 1987-April 1990

\begin{tabular}{||c|c|c|c|c|c|c||}
\hline \hline Maturity & 2 year & 3 year & 4 year & 5 year & 7 year & 10 year \\
\hline MEAN & 0.04500 & 0.04205 & 0.05447 & 0.03841 & 0.05486 & 0.05686 \\
\hline ST DEV & 0.01363 & 0.01366 & 0.01236 & 0.01300 & 0.01392 & 0.01489 \\
\hline \hline
\end{tabular}

Panel C: DRI yen interest rate swap:April 1990 - May 1996

\begin{tabular}{||c|c|c|c|c|c|c||}
\hline \hline Maturity & 2 year & 3 year & 4 year & 5 year & 7 year & 10 year \\
\hline MEAN & 0.02985 & 0.02987 & 0.02988 & 0.03000 & 0.03189 & 0.03522 \\
\hline ST DEV & 0.01206 & 0.01085 & 0.01076 & 0.01145 & 0.01083 & 0.01376 \\
\hline \hline
\end{tabular}

Panel D: DRI dollar interest rate swap:April 1990 - May 1996

\begin{tabular}{||c|c|c|c|c|c||}
\hline \hline Maturity & 2 year & 3 year & 5 year & 7 year & 10 year \\
\hline MEAN & 0.01427 & 0.01460 & 0.01387 & 0.01393 & 0.01363 \\
\hline ST DEV & 0.00488 & 0.00521 & 0.00588 & 0.00593 & 0.01363 \\
\hline \hline
\end{tabular}


Credit Risk and the Yen Interest Rate Swap Market ..................... 28

Table 3. Summary Statistics of the Fitting Error for Swaps

Table 3 provides the mean, standard deviation, minimum and maximum of the absolute values of fitting errors for swaps, defined as the absolute value of the actual price minus the estimated price. Fitted values are obtained from estimating the extended Nelson and Siegel method by minimizing the mean squared errors between observed values and actual rates. The estimation is based on one-, two-, three-, six-month and twelve month TIBOR rates and the mid-points of two-,three-, four-, five, seven-, and ten year swap rates.

\begin{tabular}{||c|c|c|c|c||}
\hline \hline & MEAN & ST. DEV & Min & MAX \\
\hline \hline 2 year & 0.02792 & 0.02053 & 0.000006 & 0.10165 \\
\hline 3 year & 0.02646 & 0.02295 & 0.000005 & 0.11783 \\
\hline 4 year & 0.01903 & 0.01501 & 0.000140 & 0.06462 \\
\hline 5 year & 0.02246 & 0.01594 & 0.000000 & 0.08194 \\
\hline 7 year & 0.03328 & 0.02266 & 0.000009 & 0.08857 \\
\hline 10 year & 0.01175 & 0.00963 & 0.000003 & 0.03753 \\
\hline Total & 0.02348 & 0.01963 & 0.000000 & 0.11783 \\
\hline \hline
\end{tabular}


Credit Risk and the Yen Interest Rate Swap Market ....................... 29

\section{Table 4. Summary Statistics of Implied Spot Rates from JGBs and Swaps}

Panel A provides the mean, standard deviation, skewness, kurtosis and autocorrelation coefficient for the weekly spot rates estimated from the 10-year off-the-run JGBs for the period April 27, 1990 to May 17, 1996. The estimation is based on the B-spline extension of the McCulloch method with four equal knots. Panel B provides the same summary statistics for the first differences of the spot rates. Panel C provides the same statistics for the weekly spot rates estimated from the swaps and TIBOR yen rates for the period April 27, 1990 to May 17, 1996. The estimation is based on the extended Nelson-Siegel method. For each estimation, we use six yen TIBOR rates for maturities of one, two, three, six, nine and twelve months and six yen swap rates for maturities of two, three, four, five, seven and ten years. Panel D provides the same summary statistics for the first differences of the spot rates.

Panel A: Level: JGBs

\begin{tabular}{||c|c|c|c|c|c||}
\hline \hline Maturity & MEAN & ST DEV & SKEWNESS & KURTOSIS & AUTO \\
\hline \hline 2 year & 3.81687 & 2.08378 & 0.37168 & -0.96377 & 0.99263 \\
\hline 3 year & 3.98263 & 1.92804 & 0.33341 & -0.93333 & 0.99254 \\
\hline 4 year & 4.20766 & 1.77436 & 0.31108 & -0.94577 & 0.99246 \\
\hline 5 year & 4.47313 & 1.63425 & 0.28452 & -1.01144 & 0.99223 \\
\hline 7 year & 4.84264 & 1.40385 & 0.28459 & -0.94078 & 0.99057 \\
\hline 10 year & 4.97832 & 1.24818 & 0.21046 & -0.95586 & 0.99013 \\
\hline \hline
\end{tabular}

Panel B First Differences: JGBs

\begin{tabular}{||c|c|c|c|c|c||}
\hline \hline Maturity & MEAN & ST DEV & SKEWNESS & KURTOSIS & AUTO \\
\hline \hline 2 year & -0.01818 & 0.10439 & 0.32670 & 0.94571 & 0.26439 \\
\hline 3 year & -0.01634 & 0.11169 & 0.41056 & 1.38400 & 0.22545 \\
\hline 4 year & -0.01455 & 0.11545 & 0.43915 & 1.29713 & 0.18650 \\
\hline 5 year & -0.01334 & 0.11353 & 0.47884 & 1.05782 & 0.16310 \\
\hline 7 year & -0.01241 & 0.11126 & 0.66719 & 1.44103 & 0.02976 \\
\hline 10 year & -0.01135 & 0.10123 & 0.32137 & 0.55748 & 0.02410 \\
\hline \hline
\end{tabular}


Credit Risk and the Yen Interest Rate Swap Market ...................... 30

Panel C: Level: Swaps

\begin{tabular}{||c|c|c|c|c|c||}
\hline \hline Maturity & MEAN & ST DEV & SKEWNESS & KURTOSIS & AUTO \\
\hline \hline 2 year & 4.06886 & 2.19240 & 0.37123 & -0.97960 & 0.99282 \\
\hline 3 year & 4.37281 & 1.97753 & 0.26946 & -0.99306 & 0.99251 \\
\hline 4 year & 4.60653 & 1.78310 & 0.20924 & -0.99928 & 0.99228 \\
\hline 5 year & 4.77723 & 1.62557 & 0.17330 & -1.00400 & 0.99210 \\
\hline 7 year & 4.99837 & 1.40935 & 0.13584 & -1.00995 & 0.99172 \\
\hline 10 year & 5.18588 & 1.24528 & 0.13313 & -0.99202 & 0.99104 \\
\hline \hline
\end{tabular}

Panel D: First Differences: Swaps

\begin{tabular}{||c|c|c|c|c|c||}
\hline \hline Maturity & MEAN & ST DEV & SKEWNESS & KURTOSIS & AUTO \\
\hline \hline 2 year & -0.01841 & 0.11829 & 0.18563 & 1.28582 & 0.11877 \\
\hline 3 year & -0.01641 & 0.12325 & 0.22421 & 1.60711 & 0.10372 \\
\hline 4 year & -0.01477 & 0.11840 & 0.24609 & 1.51064 & 0.09759 \\
\hline 5 year & -0.01354 & 0.11109 & 0.28217 & 1.30416 & 0.09292 \\
\hline 7 year & -0.01198 & 0.09958 & 0.34537 & 1.05736 & 0.07274 \\
\hline 10 year & -0.01091 & 0.09343 & 0.37209 & 1.26074 & 0.02903 \\
\hline \hline
\end{tabular}


Credit Risk and the Yen Interest Rate Swap Market ...................... 31

\section{Table 5. GMM Specification Test of the Swap Spreads}

This table presents the results of the generalized method of moments (GMM) test based on the assumption that the changes in the spot rates of the JGBs as well as the changes in the swap spreads on a spot basis follow an AR(1) process. We define the swap spread as the difference between the spot rates based on the swap rates and the JGB yields: $i^{S}(t, t+m)=i^{T}(t, t+m)+\pi(t, t+m)$. We model the change in the spot interest rate of JGBs as

$$
\Delta i^{T}(t, t+m)=\alpha(m)+\beta(m) \Delta i^{T}(t-1, t-1+m)+\sigma(m) \varepsilon_{t}
$$

and the change in the swap spread as

$$
\Delta \pi(t, t+m)=\theta(m)+\lambda(m) \Delta \pi(t-1, t-1+m)+\delta(m) \eta_{t}
$$

where $\varepsilon_{t}$ and $\eta_{t}$ are i,i,d standard normal variables and $E\left[\varepsilon_{t} \eta_{t}\right]=\rho$. We estimate the parameters of interest by matching two sets of unconditional moments of the data, the mean, standard deviation, skewness, kurtosis and autocorrelation, as well as the correlation between $\Delta i^{T}(t, t+m)$ and $\Delta \pi(t, t+m)$. The variancecovariance matrix is estimated by the Newey-West method with 15 lags. Numbers in brackets represent the standard errors of the estimates. The $p$-value represents the significance level of the $J$-statistic based on four over-identifying restrictions. The spot rates are estimated from off-the-run JGBs for the period April 27, 1990 to May 17, 1996 using the B-spline extension of the McCulloch method. The implied spot rates of swaps are based on the extended Nelson-Siegel method using six yen TIBOR rates for maturities of one, two, three, six, nine and twelve months and six yen swap rates for maturities of two, three, four, five, seven and ten years. The swap rates are the mid-points of bid-offer rates obtained from the NEEDS database of Nihon Keizai Shimbun.

\begin{tabular}{||c|c|c|c|c|c|c||}
\hline \hline & 2 year & 3 year & 4 year & 5 year & 7 year & 10 year \\
\hline \hline$\beta$ & 0.23381 & 0.22839 & 0.20334 & 0.19836 & 0.11189 & 0.06613 \\
& $(0.08024)$ & $(0.08247)$ & $(0.08361)$ & $(0.07169)$ & $(0.06473)$ & $(0.04586)$ \\
\hline$\lambda$ & -0.00236 & -0.00657 & -0.00866 & -0.00485 & -0.00600 & -0.01481 \\
& $(0.00333)$ & $(0.00326)$ & $(0.00283)$ & $(0.00240)$ & $(0.00164)$ & $(0.00256)$ \\
\hline$\rho$ & -0.08462 & -0.05395 & -0.17063 & -0.23356 & -0.43445 & -0.47727 \\
& $(0.05075)$ & $(0.05846)$ & $(0.05170)$ & $(0.04403)$ & $(0.03949)$ & $(0.05640)$ \\
\hline$\chi^{2}(4)$ & 8.58067 & 9.90499 & 11.43031 & 10.58240 & 7.90604 & 8.97767 \\
$p-$ value & $(0.07247)$ & $(0.04205)$ & $(0.02213)$ & $(0.03167)$ & $(0.09508)$ & $(0.06165)$ \\
\hline \hline
\end{tabular}


Credit Risk and the Yen Interest Rate Swap Market ....................... 32

\section{Table 6. Summary Statistics of the Swap Spreads}

Panel A provides the mean, standard deviation and autocorrelation coefficients for the yen swap yield spreads: the difference between swap rates and the par bond yields of JGBs with the corresponding maturity. Panel B provides the same statistics for the yen swap spreads on a spot basis; the difference between the implied spot rates from swaps and the implied spot rates from the JGBs. Panel C reports the mean, standard deviation and autocorrelation coefficient for the spreads of the U.S. dollar interest rate swaps. Par bond yields are based on the constant maturity treasury yields for the same period. Par bond yields are based on the spot rates estimated from off-the-run JGBs for the period April 27, 1990 to May 17, 1996 using the B-spline extension of the McCulloch method. The implied spot rates of swaps are based on the extended Nelson-Siegel method using six yen TIBOR rates for maturities of one, two, three, six, nine and twelve months and six yen swap rates for maturities of two, three, four, five, seven and ten years. The swap rates are the mid-points of bid-offer rates obtained from the NEEDS database of Nihon Keizai Shimbun. The spreads of the U.S. dollar interest rate swaps are obtained from the Data Resources Inc. database.

Panel A: Yield Basis

\begin{tabular}{||c|c|c|c|c|c|c||}
\hline \hline Maturity & 2 year & 3 year & 4 year & 5 year & 7 year & 10 year \\
\hline \hline MEAN & 0.26596 & 0.37206 & 0.38740 & 0.31287 & 0.20430 & 0.20749 \\
\hline ST DEV & 0.16904 & 0.14034 & 0.14078 & 0.15585 & 0.12144 & 0.12397 \\
\hline AUTO & 0.92052 & 0.90406 & 0.91473 & 0.94237 & 0.94798 & 0.90655 \\
\hline \hline
\end{tabular}

Panel B: Spot Rate Basis

\begin{tabular}{||c|c|c|c|c|c|c||}
\hline \hline Maturity & 2 year & 3 year & 4 year & 5 year & 7 year & 10 year \\
\hline \hline MEAN & 0.25199 & 0.39018 & 0.39887 & 0.30409 & 0.15573 & 0.20756 \\
\hline ST DEV & 0.17452 & 0.14484 & 0.13461 & 0.14595 & 0.13276 & 0.13433 \\
\hline AUTO & 0.92804 & 0.91357 & 0.91413 & 0.94487 & 0.94974 & 0.89187 \\
\hline \hline
\end{tabular}

Panel C: Dollar swap spreads: Yield Basis

\begin{tabular}{||c|c|c|c|c|c||}
\hline \hline Maturity & 2 year & 3 year & 5 year & 7 year & 10 year \\
\hline \hline MEAN & 0.29304 & 0.38502 & 0.38371 & 0.43221 & 0.45505 \\
\hline ST DEV & 0.13516 & 0.15100 & 0.15836 & 0.13230 & 0.13909 \\
\hline AUTO & 0.95202 & 0.96141 & 0.98339 & 0.97969 & 0.97964 \\
\hline \hline
\end{tabular}


Credit Risk and the Yen Interest Rate Swap Market ....................... 33

Table 7. The Relationship between the Actual Swap Rate and the Fitted Par Bond Yield

Panel A presents the regression results of the implied par bond yields from JGBs on the swap rates of the corresponding maturities; $S W(t, t+m)=\alpha(m)+\beta(m) P A R(t, t+m)$. Panel B presents the least squares regression (LS) results of the changes of implied par bond yields on the changes of swap rates of the corresponding maturities; $\Delta S W(t, t+m)=\alpha(m)+\beta(m) \Delta P A R(t+t+m)$. Numbers in brackets represent the standard errors of the estimated parameters based on the heteroscedasticity and autocorrelation consistent estimate of covariance matrix with six lags. $\chi^{2}(2)$ is a test statistic of the null hypothesis that $\alpha=0$ and $\beta=1$. $\chi^{2}(1)$ is a test statistic of the null hypothesis that $\beta=1$. Panel $\mathrm{C}$ presents the regression results using the instrumental variable (IV) estimation. Par bond yields are based on the spot rates estimated from off-the-run JGBs for the period April 27, 1990 to May 17, 1996 using the B-spline extension of the McCulloch method. The implied spot rates of swaps are based on the extended Nelson-Siegel method using six yen TIBOR rates for maturities of one, two, three, six, nine and twelve months and six yen swap rates for maturities of two, three, four, five, seven and ten years. The swap rates are the mid-points of bid-offer rates obtained from the NEEDS database of Nihon Keizai Shimbun.

Panel A: Level of Yields

\begin{tabular}{||c|c|c|c|c|c|c||}
\hline \hline Maturity & 2 year & 3 year & 4 year & 5 year & 7 year & 10 year \\
\hline \hline$\alpha$ & 0.08636 & 0.25454 & 0.34546 & 0.28394 & 0.23963 & 0.17203 \\
& $(0.01596)$ & $(0.01635)$ & $(0.01990)$ & $(0.02491)$ & $(0.23963)$ & $(0.02706)$ \\
\hline$\beta$ & 1.04647 & 1.02917 & 1.00987 & 1.00643 & 0.99270 & 1.00712 \\
& $(0.00362)$ & $(0.00364)$ & $(0.00430)$ & $(0.00518)$ & $(0.00463)$ & $(0.00525)$ \\
\hline $\mathrm{R}^{2}$ & 0.99624 & 0.99606 & 0.99429 & 0.99170 & 0.99318 & 0.99149 \\
\hline \hline
\end{tabular}

Panel B: Changes in Yields (LS Estimation)

\begin{tabular}{||c|c|c|c|c|c|c||}
\hline \hline Maturity & 2 year & 3 year & 4 year & 5 year & 7 year & 10 year \\
\hline \hline$\alpha$ & -0.00159 & -0.00119 & -0.00138 & -0.00153 & -0.00138 & -0.00178 \\
& $(0.00377)$ & $(0.00347)$ & $(0.00326)$ & $(0.00294)$ & $(0.00203)$ & $(0.00272)$ \\
\hline$\beta$ & 0.93216 & 0.93588 & 0.92277 & 0.91478 & 0.86834 & 0.82022 \\
& $(0.03509)$ & $(0.03045)$ & $(0.02785)$ & $(0.02566)$ & $(0.01839)$ & $(0.02719)$ \\
\hline $\mathrm{R}^{2}$ & 0.69200 & 0.75048 & 0.77748 & 0.80176 & 0.87646 & 0.74336 \\
\hline$\chi^{2}(2)$ & 3.97520 & 6.80963 & 10.68668 & 13.47258 & 58.79907 & 16.76215 \\
$p-$ value & 0.13702 & 0.03321 & 0.00477 & 0.00118 & 0.00000 & 0.0022 \\
\hline$\chi^{2}(1)$ & 3.87571 & 6.21191 & 9.57294 & 13.43885 & 55.46961 & 16.73311 \\
$p-$ value & 0.04898 & 0.01268 & 0.00197 & 0.00024 & 0.00000 & 0.00004 \\
\hline \hline
\end{tabular}


Credit Risk and the Yen Interest Rate Swap Market ....................... 34

Panel C: Changes in Yields (IV Estimation)

\begin{tabular}{||c|c|c|c|c|c|c||}
\hline \hline Maturity & 2 year & 3 year & 4 year & 5 year & 7 year & 10 year \\
\hline \hline$\alpha$ & -0.00504 & -0.00221 & -0.00076 & -0.00062 & 0.00005 & 0.00005 \\
& $(0.00353)$ & $(0.00299)$ & $(0.00311)$ & $(0.00292)$ & $(0.00177)$ & $(0.00275)$ \\
\hline$\beta$ & 0.75902 & 0.90474 & 0.99101 & 1.01274 & 0.98939 & 0.98812 \\
& $(0.09926)$ & $(0.09865)$ & $(0.09782)$ & $(0.08195)$ & $(0.06755)$ & $(0.09515)$ \\
\hline $\mathrm{R}^{2}$ & 0.67649 & 0.75943 & 0.78364 & 0.79961 & 0.86512 & 0.71401 \\
\hline$\chi^{2}(2)$ & 6.88926 & 1.03444 & 0.06320 & 0.15228 & 0.04075 & 0.02464 \\
$p-$ value & 0.03191 & 0.59617 & 0.96889 & 0.92668 & 0.97983 & 0.98102 \\
\hline$\chi^{2}(1)$ & 5.89377 & 0.93238 & 0.00843 & 0.02418 & 0.02464 & 0.01558 \\
$p-$ value & 0.01519 & 0.33424 & 0.92683 & 0.87641 & 0.87525 & 0.90064 \\
\hline \hline
\end{tabular}


Credit Risk and the Yen Interest Rate Swap Market ....................... 35

\section{Table 8. The Determinants of Yen Swap Spreads}

Panel A of Table 8 presents the regression results of the changes of yen interest rate swap spreads (JPSPREAD ${ }_{t}$ ) of maturity $m$-year measured in the yield basis on the changes in the Gensaki three month rates $\left(\right.$ GENSAKI $\left._{t}\right)$, the changes of the slope of the JGB yield curve measured by the $m$-year JGB spot rate minus one-year JGB spot rate $\left(\mathrm{SLOPE}_{t}\right)$, the changes of the curvature of the JGB yield curve defined by (10-year JGB spot rate + three-month Gensaki rate)/2 minus one-year JGB spot rate $\left(\mathrm{CURVE}_{t}\right)$, the changes in TED spreads measured by the three-month TIBOR yen rate minus the three-month Gensaki rate $\left(\mathrm{TED}_{t}\right)$ and the changes in the corporate bond yields issued by the Tokyo Electric Co. (CYIELD $t)$. Panel B presents the same regression results for the changes of yen interest rate swap spreads measured in the spot basis. Implied spot rates for swaps are estimated by using the extended Nelson-Siegel's method. Swaps, Gensaki and TIBOR rates are obtained from the NEEDS database. The corporate bond yields are also obtained from the NEEDS database. The JGB yield curve data is based on the B-spline method using the off-the-run JGBs. The total number of observations is 227 . The estimation is performed by the Cochran-Orcutt procedure to allow the $\operatorname{AR}(1)$ error. Numbers in brackets represent the $t$-values of the estimates.

Panel A: Yield Basis

\begin{tabular}{||c|c|c|c|c|c||}
\hline \hline & 2 year & 3 year & 5 year & 7 year & 10 year \\
\hline \hline GENSAKI $_{t}$ & -0.11617 & -0.12290 & -0.0882 & -0.04413 & -0.29079 \\
& $(-1.81559)$ & $(-1.91523)$ & $(-1.67304)$ & $(-1.09486)$ & $(-4.93508)$ \\
\hline SLOPE $_{t}$ & -0.49619 & -0.35009 & -0.34558 & -0.28045 & -0.76322 \\
& $(-4.70372)$ & $(-4.12992)$ & $(-5.73432)$ & $(-6.37522)$ & $(-9.13010)$ \\
\hline CURVE $_{t}$ & 0.075354 & 0.07737 & 0.10154 & 0.07941 & 0.32972 \\
& $(2.81226)$ & $(2.92474)$ & $(4.00018)$ & $(3.27234)$ & $(6.49588)$ \\
\hline TED $_{t}$ & 0.07303 & 0.05806 & 0.08995 & 0.05431 & 0.10921 \\
& $(1.35250)$ & $(1.11640)$ & $(2.08061)$ & $(1.80263)$ & $(2.91050)$ \\
\hline CYIELD $_{t}$ & 0.23221 & 0.25131 & 0.18428 & 0.07567 & 0.34460 \\
& $(3.62856)$ & $(3.69345)$ & $(2.94490)$ & $(1.63838)$ & $(5.87277)$ \\
\hline R $^{2}$ & 0.13412 & 0.10857 & 0.16376 & 0.24768 & 0.45203 \\
\hline \hline
\end{tabular}


Credit Risk and the Yen Interest Rate Swap Market ...................... 36

Panel B: Spot Rate Basis

\begin{tabular}{||c|c|c|c|c|c||}
\hline \hline & 2 year & 3 year & 5 year & 7 year & 10 year \\
\hline \hline GENSAKI $_{t}$ & -0.10161 & -0.09575 & -0.11485 & -0.04481 & -0.35286 \\
& $(-1.55454)$ & $(-1.50695)$ & $(-2.52223)$ & $(-1.08457)$ & $(-5.14979)$ \\
\hline SLOPE $_{t}$ & -0.43520 & -0.32084 & -0.37796 & -0.37688 & -0.87483 \\
& $(-4.07451)$ & $(-3.78699)$ & $(-7.11476)$ & $(-8.51745)$ & $(-8.99494)$ \\
\hline CURVE $_{t}$ & 0.06129 & 0.07299 & 0.11200 & 0.08592 & 0.38203 \\
& $(2.26682)$ & $(2.76046)$ & $(4.99543)$ & $(3.52460)$ & $(6.47020)$ \\
\hline TED $_{t}$ & 0.06168 & 0.05659 & 0.06269 & 0.08579 & 0.10911 \\
& $(1.14554)$ & $(1.08010)$ & $(1.62846)$ & $(2.83594)$ & $(2.49875)$ \\
\hline CYIELD $_{t}$ & 0.21727 & 0.26840 & 0.18876 & 0.09147 & 0.42221 \\
& $(3.33320)$ & $(3.97082)$ & $(3.46571)$ & $(1.94247)$ & $(6.18780)$ \\
\hline R $^{2}$ & 0.10010 & 0.11141 & 0.23519 & 0.38728 & 0.44210 \\
\hline \hline
\end{tabular}


Credit Risk and the Yen Interest Rate Swap Market ...................... 37

\section{Table 9. The Relationship between Yen Swap and Dollar Swap Spreads}

Table 9 presents the correlation coefficients among the changes of yen interest rate swap spreads, JPSPREAD, the changes of the dollar interest rate swap spreads, USSPREAD, and the changes of the interest differentials between U.S. and Japan, DIFF for different maturities. The interest rate differentials are based on the constant maturity yields of government bonds of the same maturities with swaps. Swap spreads and the constant maturity yields are obtained from the Data Resources Inc.

Panel A: Two-year

\begin{tabular}{||c|c|c|c||}
\hline \hline & USSPREAD & JPSPREAD & DIFF \\
\hline \hline USSPREAD & 1 & -0.00476 & 0.15165 \\
\hline JPSPREAD & & 1 & 0.32720 \\
\hline DIFF & & & 1 \\
\hline \hline
\end{tabular}

Panel B: Three-year

\begin{tabular}{||c|c|c|c||}
\hline \hline & USSPREAD & JPSPREAD & DIFF \\
\hline \hline USSPREAD & 1 & 0.058638 & 0.03589 \\
\hline JPSPREAD & & 1 & 0.25258 \\
\hline DIFF & & & 1 \\
\hline \hline
\end{tabular}

Panel C: Five-year

\begin{tabular}{||c|c|c|c||}
\hline \hline & USSPREAD & JPSPREAD & DIFF \\
\hline \hline USSPREAD & 1 & 0.03332 & 0.07510 \\
\hline JPSPREAD & & 1 & 0.26017 \\
\hline DIFF & & & 1 \\
\hline \hline
\end{tabular}

Panel D: Seven-year

\begin{tabular}{||c|c|c|c||}
\hline \hline & USSPREAD & JPSPREAD & DIFF \\
\hline \hline USSPREAD & 1 & 0.12394 & 0.11868 \\
\hline JPSPREAD & & 1 & 0.38042 \\
\hline DIFF & & & 1 \\
\hline \hline
\end{tabular}

Panel E: Ten-year

\begin{tabular}{||c|c|c|c||}
\hline \hline & USSPREAD & JPSPREAD & DIFF \\
\hline \hline USSPREAD & 1 & 0.05950 & 0.15123 \\
\hline JPSPREAD & & 1 & 0.45328 \\
\hline DIFF & & & 1 \\
\hline \hline
\end{tabular}


Credit Risk and the Yen Interest Rate Swap Market ...................... 38

\section{Table 10. The Lead-Lag Relationship between Yen Swap and Dollar Swap Spreads}

Panel A of Table 10 presents the regression results of the changes of yen interest rate swap spreads

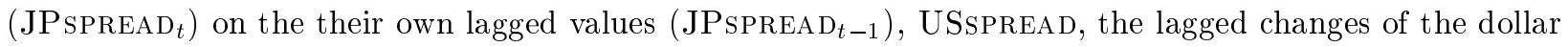
interest rate swap spreads (USSPREAD $D_{t-1}$ ), and the lagged changes of the interest differentials between U.S. and Japan $\left(\mathrm{DIFF}_{t-1}\right)$. Panel B presents the regression results of the changes of dollar interest rate swap spreads on the lagged variables. The interest rate differentials are based on the constant maturity yields of government bonds of the same maturities with swaps. Swap spreads and the constant maturity yields are obtained from the Data Resources Inc. Numbers in brackets represent the $t$-values of estimates.

Panel A: JPspread $t$

\begin{tabular}{||c|c|c|c|c|c||}
\hline \hline & 2 year & 3 year & 5 year & 7 year & 10 year \\
\hline \hline JPSPREAD $_{t-1}$ & -0.16185 & -0.25662 & -0.23926 & -0.23003 & -0.30607 \\
& $(-2.77482)$ & $(-4.53985)$ & $(-4.20606)$ & $(-3.83718)$ & $(-4.99397)$ \\
\hline USSPREAD $_{t-1}$ & 0.34491 & 0.00628 & 0.00628 & -0.26399 & -0.11398 \\
& $(2.45623)$ & $(2.07457)$ & $(0.03390)$ & $(-1.28428)$ & $(-0.48347)$ \\
\hline DIFF $_{t-1}$ & 0.08396 & 0.02452 & 0.06867 & 0.06201 & 0.09538 \\
& $(2.63777)$ & $(0.90769)$ & $(2.70867)$ & $(2.14197)$ & $(3.09629)$ \\
\hline $\mathrm{R}^{2}$ & 0.05930 & 0.07174 & 0.06191 & 0.05382 & 0.07690 \\
\hline \hline
\end{tabular}

Panel B: USspread $t$

\begin{tabular}{||c|c|c|c|c|c||}
\hline \hline & 2 year & 3 year & 5 year & 7 year & 10 year \\
\hline \hline JPSPREAD $_{t-1}$ & -0.00999 & -0.03284 & 0.00478 & -0.01679 & -0.00671 \\
& $(-0.43318)$ & $(-1.25786)$ & $(0.27770)$ & $(-1.01063)$ & $(-0.45043)$ \\
\hline USSPREAD $_{t-1}$ & -0.24396 & -0.23899 & -0.15173 & -0.07948 & 0.04291 \\
& $(-4.39164)$ & $(-4.35086)$ & $(-2.69984)$ & $(-1.39461)$ & $(0.74880)$ \\
\hline DIFF $_{t-1}$ & 0.02704 & -0.00000 & 0.00286 & 0.00173 & 0.00700 \\
& $(2.14782)$ & $(-0.00000)$ & $(0.37304)$ & $(0.21600)$ & $(0.93468)$ \\
\hline $\mathrm{R}^{2}$ & 0.06466 & 0.06428 & 0.02328 & 0.01067 & 0.00532 \\
\hline \hline
\end{tabular}


Figure 1: Swap Rates. Figure 1 presents the time series graphs of three-month yen TIBOR rates, and two- and ten-year yen swap rates for the period April 27, 1990 to May 17, 1996. The swap quotations, based on the mid-rates for the market recorded at 5 p.m., are obtained from the NEEDS database of Nihon Keizai Shimbun.

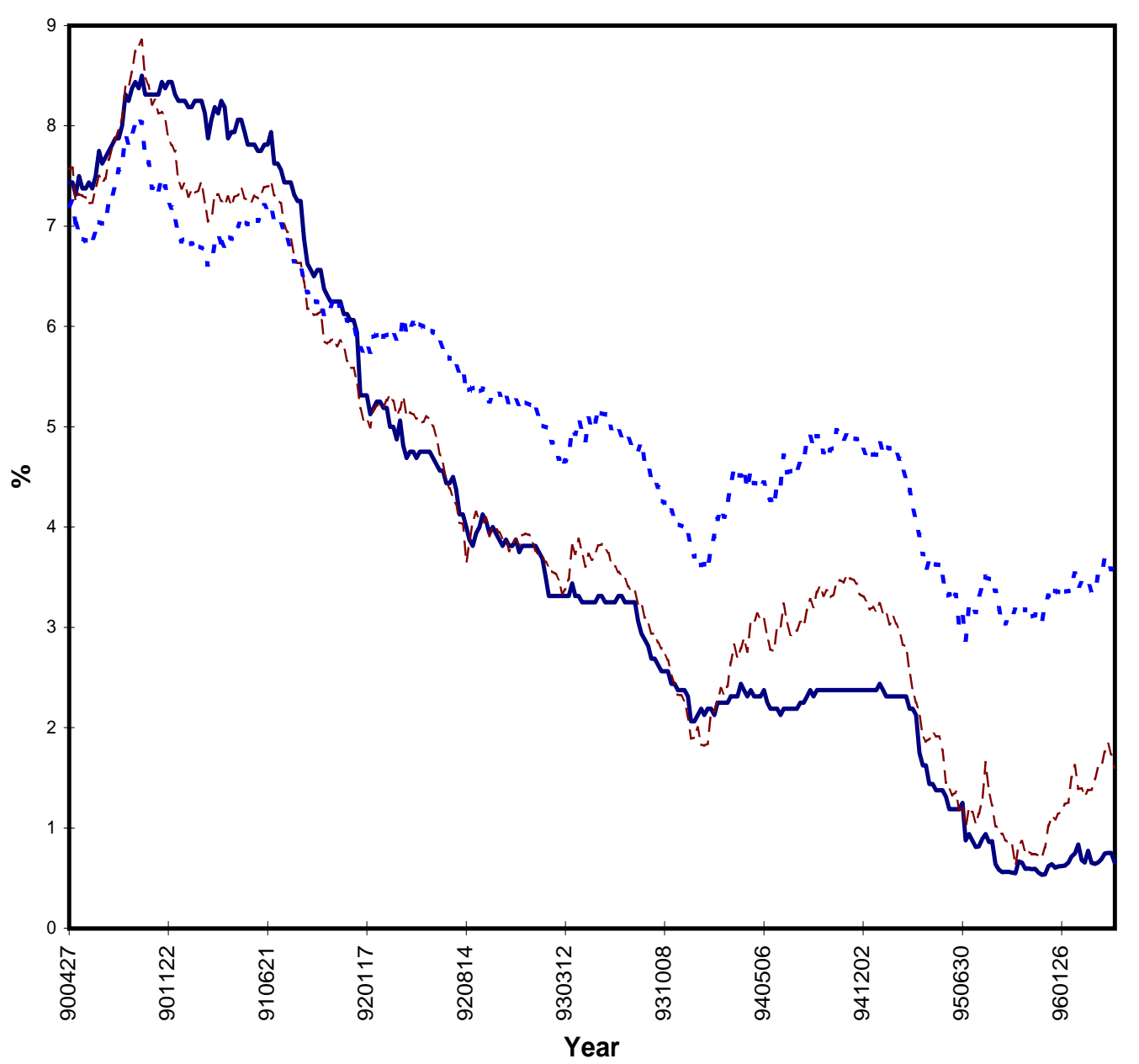


Figure 2: Swap Spreads. Figure 2 presents the two- and ten-year yen swap yield spreads: the difference between the yen swap rates and the par bond yields of JGB's with the corresponding maturity. Par bond yields are based on the spot rates estimated from off-the-run JGB's for the period April 27, 1990 to May 17, 1996 using the basis-spline extension of the McCulloch method. The swap rates are the mid-points of bid-offer rates obtained from the NEEDS database of Nihon Keizai Shimbun.

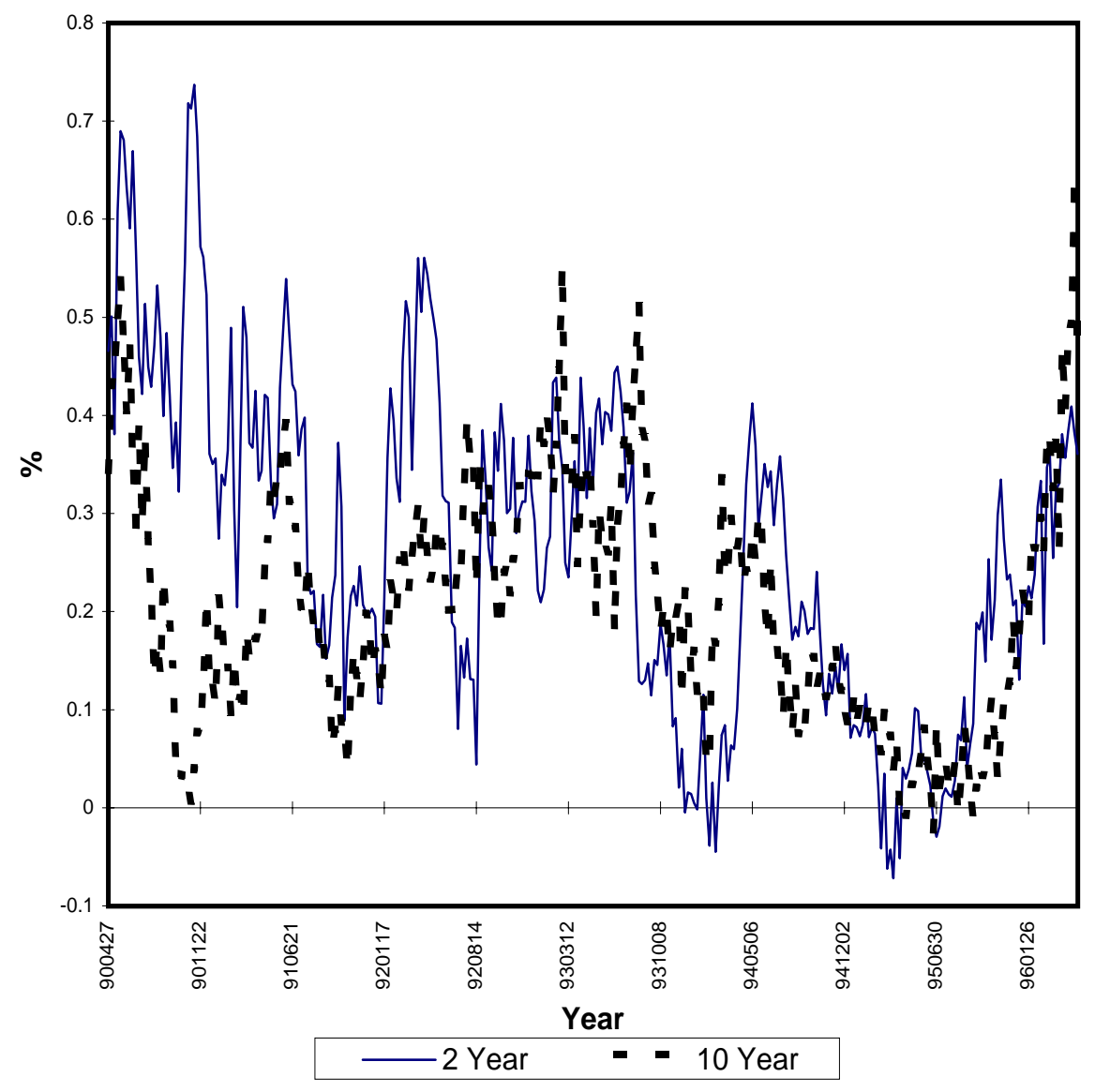


Figure 3: Dollar and Yen Swap Spreads. Figure 3 presents the mean of the yen swap spread and the dollar swap spread for the period April 27, 1990 to May 17, 1996. The yen swap spread is defined as the difference between the yen swap rates and the par bond yields of JGB's of the corresponding maturity. Yen par bond yields are based on the spot rates estimated from off-therun JGB's for the period April 27, 1990 to May 17, 1996 using the basis-spline extension of the McCulloch method. The yen swap rates are the mid-points of bid-offer rates obtained from the NEEDS database of Nihon Keizai Shimbun. U.S. dollar interest rate swaps are computed based on data from the Data Resources Inc. database.

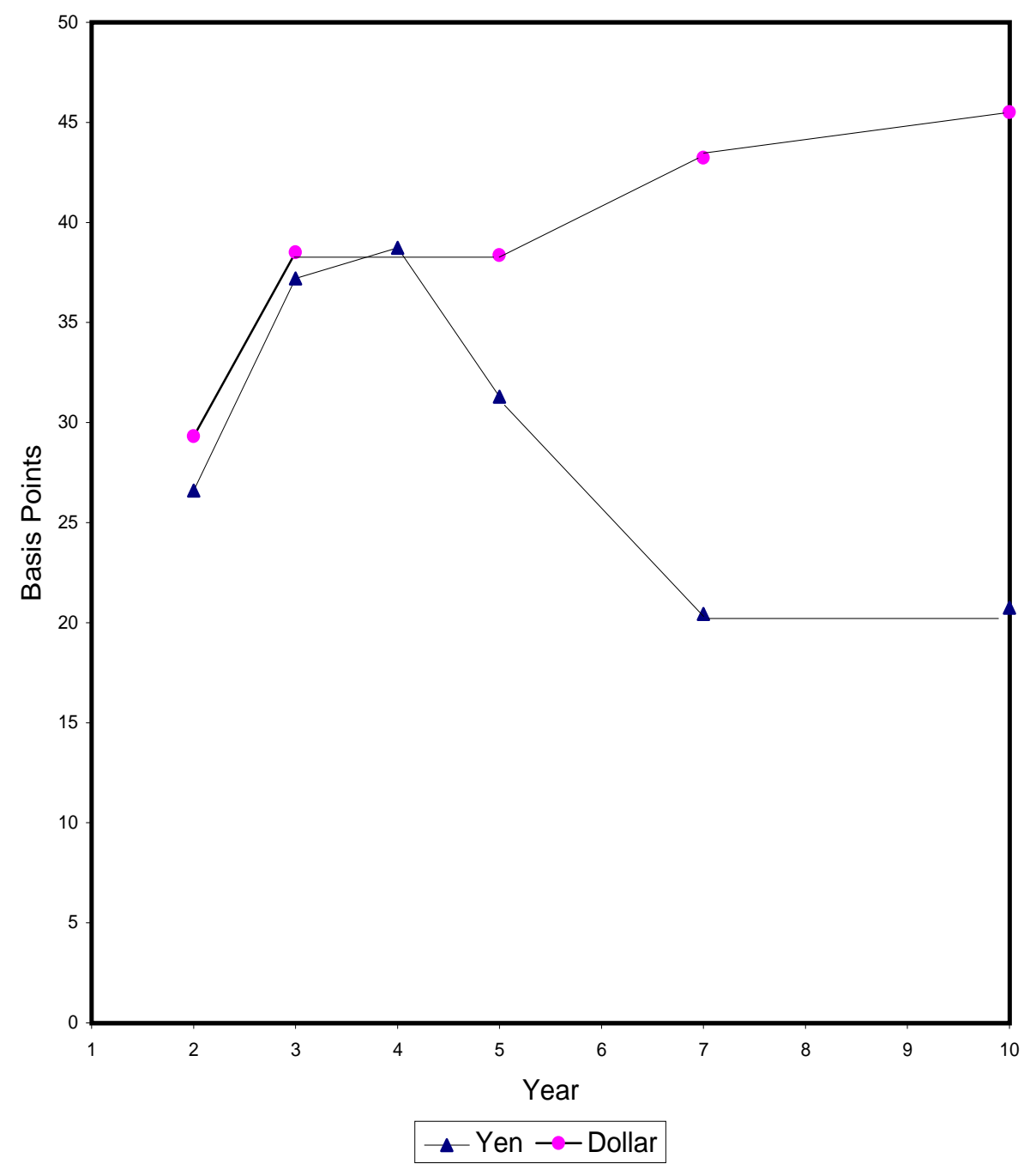

